\title{
El problema historiográfico de la transición del esclavismo al colonato
}

\author{
The historiographic problem of the transition of Slavery to Colonate
}

Fecha de recepción: septiembre de 2018. Fecha de aceptación: octubre de 2018.

\begin{abstract}
Resumen
El presente trabajo se propone hacer un recorrido historiográfico sobre el debate de la transición del esclavismo al colonato en el Imperio Romano. Se señalan las influencias ideológicas y culturales que influyeron decididamente en la construcción de este relato historiográfico, así como también sus debilidades conceptuales y las alternativas actuales de investigación que pueden alumbrar nuevas perspectivas.
\end{abstract}

\begin{abstract}
The present work intends to make a historiographical journey about the debate of the transition from slavery to colonate in the Roman Empire. The ideological and cultural influences that decisively influenced the construction of this historiographical narration, as well as its conceptual weaknesses and the current research alternatives that can illuminate new perspectives are pointed out.
\end{abstract}

\section{Introducción}

En ocasión de la publicación de la inscripción del Saltus Burunitanus, una fuente epigráfica del siglo II d. C. proveniente del norte de África y cuyas consecuencias para el estudio del colonato romano serían extremadamente importantes, Theodor Mommsen pudo declarar, con absoluta seguridad, que esta temprana referencia a un sistema basado en el pequeño arrendamiento campesino, base posterior del colonato bajoimperial, había sido siempre la base de las relaciones sociales agrarias en Italia, desde el Rey Rómulo hasta el Rey Humberto. ${ }^{1}$ ¿Qué razones daba Mommsen para justificar tal afirmación? Casi podríamos decir que apelaba al sentido común. La pequeña propiedad y la libre contratación eran una forma más adecuada per se para la labranza y para los cultivos arborícolas que el trabajo esclavo (idem). Esta pequeña propiedad campesina, que Mommsen caracterizaba como una relación natural, pudo haber adquirido distintas formas durante la historia de Roma (cliente, arrendatario libre, colono servil), pero su esencia se mantuvo, al parecer, intacta. ${ }^{2}$
Palabras clave

Esclavitud Colonato Arrendamiento Imperio Romano
Keywords

Slavery Colonate Tenancy Roman Empire
1. "Der Colonat an sich, das heisst die bäuerliche Kleinpacht, ist so alt und so jung wie Italien und war und ist unter König Romulus wie unter König Humbert wesentlich gleichartig beschaffen" (Mommsen, 1880: 385-411, 408).

2. "Dass diese natürlichen Verhältnisse zu allen Zeiten und namentlich auch in der Epoche der römischen Kaiserherrschaft zur Geltung gelangt sind, wird für denjenigen, dem die Bronnen der Kunde wirklichen römischen Lebens, die Pandekten oder die Inschriften, fliessen, eines Beweises nicht bedürfen.", idem. 
3. De aquí en adelante citaremos el original en italiano.

4. “...una società e un'agricoltura 'schiavistiche' nel senso forte del termine." (ibidem: 491).

5. “...quando le fonti consentono di conoscere le condizioni concrete degli schiavi, si vede che hanno famiglia, coltivano piccole propietà e usufruiscono di una sostanziale autonomia produttiva. In questa prospettiva, la loro situazione materiale

era analoga a quella dei fittavoli liberi, i coloni, e corrisponde bene alla celebre definizione di Ulpiano: servus quasi colonus." (ibidem: 494).

6. “...al declino e alla definitiva sparizione della villa schiavistica, che si risolve nella dissoluzione del modello di produzione accentrata tipico di quella forma economica e nella creazione di un modello di villa profondamente diverso, funzionale a sistemi di produzione decentrata e di rendita accentrata." (ibidem: 495).

7. "Nel corso della trasformazione, l'organizzazione della manodopera su cui si fondava l'agricoltura schiavistica divenne obsoleta, (continúa en página 154)

8. "Da un punto di vista meramente produttivo, che il colonus fosse libero o schiavo non comportava sostanziali differenze nell'organizzazione della propietà, specie nel caso della colonia parziaria che, per sua natura, comme dimostrano numerose esperienze premoderne di sharecropping, annullava l'alienazione

fra terra, lavoro e lavoratori

lamentata dai teorici dell'aricoltura schivistica." (ibidem: 501).

9. "non più bande ribelli di schiavi dispersi negli agri pecuarii e di sottoproletariato rurale, ma contadini solidali con i padroni." (ibidem: 504).

10. “...l'assestamento, con la pace augusta, dell'economia su ritmi più 'naturali', adeguati alle risorci materiali e demografiche dell'Italia, rispetto alla fase di economia drogata che va all'incirca dal 160 al so a.C." (Vera, 1992-1993: 297).

11. "L'azienda schiavistica era 'anelastica' per difetti strutturali, di funzionamiemto, come si è sostenuto: anelastico era anche il costo globale, che non poteva scendere oltre certi limiti; e che pertanto ne determinò prima l'economicità e successivamente l'anticonomicità." (ibidem: 307).

12. Nos basamos aquí en las advertencias que Pierre Bourdieu, Jean-Claude Chamboredon y JeanClaude Passeron realizaron acerca de la influencia de los prejuicios y del sentido común en la conformación del objeto de investigación, (continúa en página 154)

13. Seguimos aquí los análisis sobre la visión romántico-expresivista de Berlin (1999) y Taylor (1975).
El artículo de Mommsen tiene ya casi cientocuarenta años pero no puede decirse que haya perdido vigencia. Hace algunos años, AHAMyM publicó la traducción de un artículo de Domenico Vera cuyo título rezaba "Ser esclavo de la tierra en la Italia tardoantigua: La racionalidad de una dependencia" (Vera, 2010: 35-53, traducción de Vera, 2007: 489-505). ${ }^{3}$ Esta "racionalidad" era muy similar a la esbozada por Mommsen. Señalaba Vera que entre los siglos II a. C. y II d. C. había existido una economía esclavista, "en el más fuerte sentido del término", ${ }_{4}^{4}$ que luego dio paso a partir del siglo III d. C. a otra forma de dependencia rural, el colonato. Esta última relación social se caracterizaba por la instalación del esclavo como un pequeño productor autónomo junto a su familia, de forma similar al colono arrendatario romano. ${ }^{5} \mathrm{En}$ términos generales, Vera describía esta transformación como el pasaje de una economía centralizada, basada en el trabajo esclavo, a una nueva economía caracterizada por la descentralización de las actividades productivas, en manos ahora de colonos autosuficientes, pero de "rendimiento concentrado". ${ }^{6}$ Estos cambios eran atribuidos a transformaciones económicas internas, entre las cuales sobresalía la obsolescencia de la esclavitud, cuyo mantenimiento se había tornado demasiado costoso, resultando imperativo entonces la parcelización de la fuerza de trabajo en unidades domésticas familiares, proceso que se daba al mismo tiempo que la propiedad de la tierra se concentraba en grandes latifundios. ${ }^{7}$ Incluso el hecho de que este colono fuera libre o esclavo no tenía casi importancia ya que, a ojos de Vera, la propia forma de producción anularía el proceso de enajenación entre el productor directo y la tierra. ${ }^{8} \mathrm{La}$ racionalización de las relaciones agrarias que supuestamente habría traído la pequeña producción campesina se observaba recorriendo las tierras de Italia en el siglo VI: una amplia pacificación rural y una corriente de solidaridad entre campesinos y propietarios. ${ }^{9}$

Podemos encontrar en otros trabajos de Vera caracterizaciones similares. La más llamativa tal vez sea su calificación de la esclavitud romana como una etapa fugaz de "economía drogada", consecuencia del gran aflujo de riquezas desde las provincias conquistadas hacia la península itálica. ${ }^{10}$ Pero una vez terminada esta etapa, el escenario rural volvía a la normalidad de una economía campesina de autosuficiencia. La esclavitud constituía un atributo superficial y pasajero, atribuible a condiciones económicas excepcionales que permitieron superar momentáneamente su inefable talón de Aquiles: la inelasticidad de costos. ${ }^{11}$ Tarde o temprano la esencia inalterable de la economía campesina se imponía por las propias condiciones naturales.

Lo que analizaremos a continuación es cómo pudo imponerse en la historiografía semejante relato cuyas fundamentaciones últimas descansan en razonamientos sobre cuán "natural" pueda ser una relación social. Pero para ello debemos remontarnos mucho más allá incluso de la época de Mommsen, hasta principios del siglo XIX, y adentrarnos en la configuración de la visión romántica de la antigüedad y y del campesino. ${ }^{12}$

\section{El romanticismo alemán y la economía política clásica}

Como es sabido, hacia finales del siglo XVIII la cultura alemana se vio influida por el movimiento romántico conocido como Sturm und Drang. Dentro del amplio alcance que esta corriente intelectual tuvo en las letras y en las artes europeas, hay un aspecto esencial del cual nos interesa ocuparnos: la configuración de una visión del ser humano centrada en sus formas de expresión, que en la literatura crítica sobre el tema fue calificada como una "antropología expresivista". ${ }^{13}$ Frente a la antropología de la Ilustración, acusada por los románticos de "objetificar" la naturaleza humana, de fragmentar la mente humana en distintas facultades, de 
separar el alma y el cuerpo, y de establecer una noción calculadora de la razón al margen de los sentimientos y de la voluntad (Taylor, 1975: 13), la noción expresivista, desarrollada fundamentalmente por Herder, implicaba suponer que la principal función del hombre era su capacidad de expresarse, de hablar. Cualquier cosa que un hombre hiciera expresaba su naturaleza, y si algo se lo impedía, se trataba de un hombre atrofiado, refrenado, cuya energía estaba aprisionada (Berlin, 1999: 58). Esta cualidad expresiva del ser humano implicaba una noción unitaria de la vida, imposible de dividir artificialmente en distintos niveles (vida contra pensamiento, sentimiento contra racionalidad, conocimiento contra voluntad), pues el ser humano no era un animal con razón agregada sino una forma nueva totalmente indivisible (Taulor, 1975: 21). La nueva noción del ser humano implicaba también una nueva relación con el mundo natural. Mientras la Ilustración había desarrollado una concepción de la naturaleza, incluida la humana, como un conjunto de hechos objetivados con los cuales el sujeto tenía que lidiar para adquirir conocimiento y poder actuar, los románticos consideraron esta visión como un destrozo de la unidad de la vida, en la cual la naturaleza debía ser la inspiración y el motivo del pensamiento y la voluntad (ibidem: 22-23). El mundo "objetificado" de la Ilustración era visto como un exilio, lo que generó una nostalgia por un pasado en el cual esta unidad no estuviera desgarrada, un mundo en donde el sujeto y sus aspiraciones se reconocieran en la naturaleza como una sola. Ese mundo era la Antigüedad clásica. ${ }^{14}$

¿Por qué la polis griega era un ideal expresivista para el romanticismo alemán? Porque frente a la sociedad moderna del interés individual que la Ilustración representaba, conformada por sujetos atomizados, moralmente autosuficientes, cuyas relaciones entre sí eran meramente externas, la antigua polis suponía para la generación romántica un profundo lazo de unidad que pudo conciliar, al mismo tiempo, la fraternidad entre los sujetos junto a su más alto sentimiento del yo. En esta unidad se compartían las más altas preocupaciones, que constituían la propia vida de la comunidad, por encima de la simple auto-preservación individual. ${ }^{15}$ Quien posiblemente haya expresado mejor la distancia entre la polis y la sociedad moderna fue Schiller, preocupado especialmente por trazar las desviaciones que había sufrido el ser humano en su larga evolución histórica. La división del trabajo de las modernas sociedades de clase produjo, a ojos de Schiller, la extrema especialización del hombre contemporáneo, transformándose así lo que era una unidad viva, bajo los griegos, en una interdependencia mecánica. ${ }^{16}$ Los sujetos no son ya seres concretos sino meros constructos intelectuales, por lo cual no se siente identificados con el Estado, que ha perdido toda su autoridad y deviene así en un mero poder gobernante y opresivo (Taylor, 1975: 28). ${ }^{17}$

La contraposición que Schiller hacía entre el primitivo hombre concreto, peculiar e históricamente determinado, y el hombre genérico y abstracto de la sociedad moderna, ejercería una gran influencia en la filosofía de Hegel. ${ }^{18}$ Su concepción filosófica de la historia reflejaba esta visión romántica, particularmente en lo que hace a la descripción del desarrollo histórico de Grecia y Roma. Mientras que el principio griego se basaba en la naturalidad y particularidad de los individuos, el romano postulaba una abstracción universal que colocaba al Estado en contraposición al individuo, devenido éste en una persona jurídica cuya existencia estaba determinada por la mera propiedad de bienes; una existencia formal indiferente a las "determinaciones concretas del espíritu". ${ }^{19}$ Las consecuencias de este principio para el mundo romano no podían ser peores: el predominio del derecho privado suponía la descomposición de la vida política. El estado era un cadáver putrefacto cuya única vida era la de los gusanos, esto es, la de las personas privadas. ${ }^{20}$ Este estado de enajenación de las relaciones sociales empeoraba por otro factor que se agregaba al derecho privado y a la contractualización de la vida: la esclavitud. Hegel la caracterizaba como una institución corruptora, propia de una sociedad improductiva y degenerada. ${ }^{21}$ De todas
14. "Once upon a time we were integral, we were Greeks. (This is the great myth of the Greeks, which is historically no doubt quite absurd, but dominated the Germans in their political helplessness -Schiller and Hölderlin and Hegel and Schlegel and Marx.) We were children playing in the sunlight, we did not distinguish between necessity and freedom, between passion and reason, and this was a happy and innocent time. But this time is past, innocence is gone; life no longer offers us these things; what we are now offered as a description of the universe is nothing but a grim causal treadmill" (Berlin, 1999: 87).

15. Estas nociones se aplicaron también a la civitas romana primitiva, como lo hizo José Luis Romero en La cultura occidental, en donde contraponía el ideal romano de vida, de virtud republicana como realización de servicio a la comunidad,

(continúa en página 154)

16. "Jene Polypennaur der griechischen Staaten, wo Jedes Individuum eines unabhängigen Leben geno , und wenn es Noth that, zum Ganzen werden konnte, machte jetzt einen kunstreichen Uhrwerke Platz, wo aus der Zusammenstückelung unendlich vieler, aber lebloser, Theile ein mechanisches Leben im Ganzen sich bildet." (Schiller, 1875: 149).

17. A continuación Taylor hace un sugerente comentario sobre la actualidad de la teoría romántica de la expresión...

(continúa en página 154)

18. Sobre la influencia de Schiller sobre Hegel, véase Kaufmann (1978: 18-31).

19. "Im griechischen Prinzip haben wir die Geistigkeit in ihrer Freude, in ihrer Heiterkeit und in ihrem Genüsse gesehen: der Geist hatte sich noch nicht in die Abstraktion zurückgezogen, er war noch mit dem Naturelemente. (continúa en página 154)

20. “Der lebendige Staatskörper und die römische Gesinnung, die als Seele in ihm lebte, ist nun auf die Vereinzelung des toten Privatrechts zurückgebracht. Wie, wenn der physische Körper verwest, jeder Punkt ein eigenes Leben für sich gewinnt, welches aber nur das elende Leben der Würmer ist, so hat sich hier der Staatsorganismus in die Atome der Privatpersonen aufgelöst." (ibidem: 384).

21. Hegel colocaba el gran desarrollo de la esclavitud ya en la época del conflicto entre patricios y plebeyos, pero esta descripción vale también para el período posterior, como se desprende de su propio relato: "Alle obrigkeitliche und richterliche Gewalt und alles Grundeigentum des Staats befand (continúa en página 155) 
22. Precisamente para Hegel las fiestas campesinas primitivas eran el único aspecto destacable de la religión romana (ibidem: 355 ).

23. "The experience of all ages and nations, I believe, demonstrates that the work done by slaves, though it appears to cost only their maintenance, is in the end the dearest of any. A person who can acquire no property, can have no other interest but to eat as much, and to labour as little as possible. Whatever work he does beyond what is sufficient to purchase his own maintenance, can be squeezed out of him by violence only, and not by any interest of his own." (Smith, 1982: 387-388).

24. "The natural effort of every individual to better his own condition, when suffered to exert itself with freedom and security, is so powerful a principle, that it is alone, and without any assistance, not only capable of carrying on the society to wealth and prosperity, but of surmounting a hundred impertinent obstructions with which the folly of human laws too often incumbers its operations; though the effect of these obstructions is always more or less either to encroach upon its freedom, or to diminish its security." (ibidem: 540).

25. "To the slave cultivators of ancient times, gradually succeeded a species offarmers known at present in France by the name of Metayers.

They are called in Latin, Coloni Partiarii. (...) Land occupied by such tenants is properly cultivated at the expence of the proprietor (continúa en página 155)

26. "A small proprietor, however, who knows every part of his little territory, who views it with all the affection which property, especially small property, naturally inspires, and who upon that account takes pleasure not only in cultivating but in adorning it, is generally of all improvers the most industrious, the most intelligent, and the most successful." (Smith, 1982: 423).

27. "It is a truism to assert, that labour extorted by fear of punishment is inefficient and improductive." (Mill, 1895: 176).

28. "Until, however, slavery assumes the mitigated form of villenaige, in which not only the slave has a property and legal rights, but his obligations are more or less limited by usage, and he partly labours for his own benefit, his condition is seldom such as to produce a rapid growth of population." (ibidem: 175).

29. "The fixity of tenure which the metayer, so long as he fulfils his known obligations, possesses by usage, although not by law, gives him the local attachments, and almost the strong sense of personal interest, characteristics of a propietor." (ibidem: 216). formas, el principio romano era una etapa necesaria en el desarrollo histórico al dar nacimiento a la idea de persona, entendida como un sujeto abstracto portador de un derecho de propiedad, desligado de roles sociales o políticos. La transición de una sociedad campesina, asentada en la tradición del culto a la naturaleza y en las relaciones personales, a una sociedad regida por el derecho contractual y basada en el trabajo esclavo, era el destino romano. ${ }^{22}$

Si por un lado la filosofía alemana había impuesto la noción de una totalidad armónica, luego degenerada por el desarrollo del derecho, de la esclavitud y del comercio, la incipiente economía política de finales del siglo XVIII abonaría la idea de la inferioridad productiva intrínseca de la esclavitud respecto del trabajo libre. Adam Smith señalaba que el trabajo esclavo era el más costoso de todos debido a que no existía ninguna motivación o interés en la labor de alguien que no era libre. ${ }^{23}$ Llamativamente Smith no basaba esta afirmación en ningún cálculo de costos y beneficios. Ciertamente no habría podido hacerlo ya que las evidencias de que el trabajo esclavo podía ser extremadamente rentable eran abrumadoras, como cualquier vistazo a la producción de azúcar, algodón y tabaco en Brasil, el Caribe y el sur norteamericano hubiera demostrado. La razón de tal afirmación estribaba sencillamente en una cuestión ideológica: la idea de que la libertad económica era el motor del crecimiento y del desarrollo. ${ }^{24}$ Desde Smith el principio de que la condición óptima para la creación de riqueza era aquella en la cual se permita a los individuos invertir libremente en las actividades que les reportasen mayores beneficios, y que al mismo tiempo se les asegurase el disfrute de éstos, se ha vuelto una noción de sentido común tanto en la economía mainstream como en el gran público. Naturalmente la historiografía no pudo evadirse de este influjo. El propio Smith proporcionaría el relato sobre la transición de la esclavitud al colonato, que luego se repetetiría hasta el hartazgo: los antiguos esclavos, ineficientes, fueron finalmente reemplazados por colonos libres. Éstos, al estar mucho más interesados en el trabajo por recibir como ingreso una parte de la producción, podían pagar una mayor renta al propietario. ${ }^{25}$

En detrimento de la plantación esclavista se alzaba entonces la figura del pequeño campesino propietario. Si por un lado Smith se encargaba de elogiar la venerable institución de la pequeña propiedad como un reservorio de valores morales y de eficiencia económica, ${ }^{26}$ quien llevaría más lejos las consecuencias de tales afirmaciones sería John Stuart Mill. En sus Principles of Political Economy emprendería una verdadera cruzada en defensa de la productividad de todas las formas de economía campesina: pequeña propiedad, aparcería o arrendamiento. Se acompañaba esto naturalmente de una feroz crítica de toda forma de trabajo coactivo, la esclavitud el primero de ellos, como improductivo e ineficaz. ${ }^{27}$ Mill tampoco ahorraba críticas hacia el espíritu cruel de los romanos por su uso masivo de la esclavitud, aunque destacaba que la esperanza de la manumisión y luego la instalación del esclavo con su familia mitigaron los males de esta institución. ${ }^{28}$ Pero si Smith apenas había presentado algún cálculo que sustentara la suposición de esta intrínseca superioridad productiva del trabajo libre, Mill basaba prácticamente todo su caso en citar a párrafos enteros los relatos sobre los campesinos suizos de Sismondi. Éste, un inveterado defensor de la pequeña economía campesina frente al implacable desarrollo de la agricultura capitalista, había creído encontrar una verdadera Arcadia moderna en los valles de Suiza. Sismondi defendía incluso el sistema de aparcería, señalado en su época como un sistema ineficaz que no alentaba la inversión, al sostener que la enajenación que podía sentir el aparcero por la tierra podía solucionarse si por la ley o por la costumbre se le aseguraba la tenencia. ${ }^{29}$ Ya Sismondi había aplicado estos preceptos a la historia del imperio romano en su Histoire de la Chute de l'Empire romain, donde argumentaba que una de las causas de la decadencia del imperio fue la pobre condición 
del cultivador libre, en general un colono arrendatario, y la gran distancia que mediaba entre éste y los grandes propietarios. ${ }^{30}$ No es difícil ver aquí uno de los mitos románticos más difundidos e influyentes: el culto del campesino. Componente fundamental de las corrientes románticas decimonónicas, se ensalzaban las costumbres "naturales" del campesino en contraposición al decadente hombre de las ciudades y su corruptora corriente cosmopolita. ${ }^{31}$ En la historia de Roma encontrarán los románticos un terreno fértil para ejemplificar tanto las bondades de una sociedad campesina como los estragos que supuso su desestructuración debido al desarrollo de la esclavitud mercantil.

\section{Origen y desarrollo del problema del reemplazo de la esclavitud por el colonato}

En la discusión historiográfica sobre el fin de la esclavitud y el surgimiento del colonato encontraremos todos los ingredientes del relato romántico. El primer trabajo moderno sobre este problema pertenece a Savigny, máximo exponente de la Escuela Histórica del Derecho. En una conferencia dictada en 1822, Savigny marcó por primera vez las características fundamentales de la figura del colono bajoimperial: éste no era un trabajador dependiente o un jornalero, tal como las primitivas teorías del siglo XVI habían sostenido, sino un campesino arrendatario, ligado a la tierra por su condición jurídica y cultivador por su propia cuenta de una cierta extensión de tierra, por la cual entregaba a cambio al propietario una parte de la producción, en especie o en dinero (Savigny, 1823: 18). Su condición era la de un hombre libre, acorde al concepto del derecho clásico de la figura del colonus o inquilinus, sin rastro alguno de una relación de dependencia personal. ${ }^{32}$ Pero el problema se suscitaba a la hora de explicar por qué un hombre que era libre veía coartada su libertad de movimiento. En este sentido Savigny descartó buscar los orígenes de esta institución en el pasado romano, debido a que consideraba que la esclavitud había reemplazado cualquier otro tipo de relación personal que pudiera llegar a tener un parecido con el colonato, como era el caso de la clientela republicana. ${ }^{33}$ Este rechazo de Savigny a hacer descender directamente el colonato del pasado le llevó a esbozar, si bien como una posibilidad remota, la célebre idea de entender esta institución como un estatus intermedio entre la libertad y la esclavitud, en cuya formación original habrían confluido tanto la sumisión voluntaria del campesinado al poder del propietario, 34 como una manumisión incompleta del esclavo, con la particular restricción de no poder abandonar el terreno cultivado. ${ }^{35}$ No obstante, manteniéndose fiel a su condición de jurista, Savigny rechazó la plausibilidad de tales conjeturas por considerarlas totalmente contrarias al espíritu del derecho romano, que no contemplaba bajo ningún punto de vista ni una servidumbre voluntaria ni una manumisión incompleta (ibidem: 25).

Si bien el trabajo de Savigny poseía un enfoque predominantemente jurídico, dejaba entrever también razonamientos económicos: el advenimiento del colonato era necesario porque las condiciones que suponía para le explotación de la tierra satisfacían, mucho mejor que la esclavitud, las necesidades tanto de las clases propietarias como del propio desarrollo de la agricultura. Destacaba especialmente las limitaciones que existían sobre la propiedad de la tierra (imposibilidad de venderla sin el colono al que estaba adherida), por suponer que estas medidas respondían a un interés público, tanto por el pago de los impuestos como también por las ventajas que esta institución suponía para el correcto cultivo de la tierra. ${ }^{36} \mathrm{Al}$ ser el colonato la institución necesaria para esa etapa de la historia de Roma, Savigny consideraba que la esclavitud se vería afectada mediante una paulatina transformación en la cual el esclavo adquiriría los rasgos del colono. ${ }^{37}$
30. "La population rurale dans tout l'empire romain étoit divisée en déux classes: les colons libres et les esclaves, qui différoient bien plus de nom que par des droits réels. Les premiers cultivoient la terre

(continúa en página 155)

31. Mill llegaba incluso a citar al poeta romántico Wordsworth como prueba de las bondades de la sociedad campesina: "No other agricultural population in England could have furnished the originals of Wordsworth's peasantry" (Mill, 1895: 179). La extensión del mito es abrumadora: “Además de un género literario propio, el idilio pastoril, (continúa en página 155)

32. "Dieses folgt daraus, dass teils die alten Juristen nicht mehr und unzweideutiger davon sprechen, teils auch kein sicherer Kunstausdruck dafür vorhanden ist; denn gerade die Ausdrücke Colonus und Inquilinus, die späterhin so entschiedenn dafür gebraucht werden, bedeuteten damals regelmässig etwas ganz anderes, nämlich gewöhnliche freie Pächter und Mieter, die in gar keiner persönlichen Abhängigkeit standen." (ibidem: 21).

33. "In der Mitte zwischen heiden liegt eine Zeit von vielen Jahrhunderten, in welcher das einfache, strenge Sklavenverhältnis an die Stelle fast aller andern Arten persönlicher Abhängigkeit getreten war." (ibidem: 22).

34. Ibidem (23), en base a un pasaje de Salviano (De Gubernatione Dei, V, 8, 43.) del siglo V d. C., que denunciaba la opresión impositiva que sufrían los campesinos, quienes preferían convertirse en colonos de los poderosos.

35. Ibidem (24), en base al calificativo patronus con el que las fuentes referían tanto al terrateniente de colonos como al propietario de esclavos.

36. "Es war also in der Tat nur das öffentliche Interesse, welches jene Beschränkungen veranlasste, obgleich dadurch mittelbar die Colonen einen ähnlichen Schutz gegen die Willkühr der Gutsherren erhielten, wie durch ein eigenes Recht am Boden. Jenes öffentliche Interesse aber bestand zunächst und hauptsächlich in der polizeilichen Sorge für die Landescultur, die man durch die Begünstigung dieses Verhältnisses vorzugsweise zu befördern glaubte." (ibidem: 11).

37. "Nunmehr bestanden die Sklaverei und der Colonat neben einander, aber jene wurde selbst zum Teil dem Colonat näher gebracht, welcher den herrschenden Ansichten und wohl auch den Bedürfnissen der Gegenwart mehr als sie entsprach." (ibidem: 22). Es probable que Savigny estuviese pensando aquí en la figura del servus quasi colonus. 
38. Esta transformación resulta evidente para Schultz en la mención de Columela del consejo de Publio Volusio: "Und wenn der Compilator des Columella $(I, 7)$ den reichen Consular L. Volusius sagen lässt, das Gut sei das Glücklichste, welches colonos indigenas haberet et tanquam in paterna possessione natos iam inde a cunabulis longa familiaritate retineret, so spricht er leider nicht mehr von jenem alten Familienleben der Patrone und Colonen, welches Jahrhunderte hindurch die Hörigen mit ihren Gutsherren verband, sondern es ist schon von dem Colonat die Rede, welches bei zunehmendem Druck in die glebae adscriptio ausartete, und zwangsweise die ehemalige Gewohnheit der Treue in ein unauslöslich bindendes Rechtsverhältnis umgestaltete." (ibidem: 350).

39. “Der Patronus wie der Colonus wussten ja beiderseits genau, wie viel das Gut in bessern und in schlechtern Jahren eintrug, und was der Colonus bedurfte und was ihm zukam, stand durch hundertjährige Gewohnheit (continúa en página 155)

40. "Das alt gewohnte Vertrauen musste schon sehr gestört sein, wenn der Patron die Pachtung auf bestimmte Zeit abzuschliessen und seine Rechte gegen den Colonus durch Contract strenger festzusetzen und zu verwahren veranlasst sein sollte." (Schultz, 1833: 352).

41. "Am häufigsten geschah solche Verpachtung jedoch mittelst Parzellierung der

Felder, indem der Patron sich

die Villa vorbehielt." (idem).

42. "Bei Latifundien ist dagegen stets eine Menge dienender Hände nötig, und überall wo sich deren in grosser Anzahl finden, gehört es zu den Hauptfragen über den Zustand

des gemeinen Volkes, in welcher Weise dem angedeuteten hier vorhandenen Bedürfniss genügt werde. (continúa en página 156)

43. “Der Ackerbau trägt ein gewisses Naturgesetz in sich, was unter Voraussetzung änhlicher factischer Umstände, je nachdem er im Kleinen oder Grossen betrieben wird, sehr leicht auch änhliche Rechtsverhältnisse nach zu ziehen pflegt." (ibidem: 76).

44. "Es war factisch nahezu derselbe Zustand, der nachher

im Colonat zu einem rechtlichen wurde." (Puchta, 1842: 436).

45. "Jenen faktischen zustand in einen rechtlichen zu verwandeln, und dadurch den Sicher und die

Betriebsamseit jener unfreien Arbeiter

anzuspornen, sich selbst aber eine erhebliche Rente von dem Gut su sichern, konnte unter Umständen

den Herren, namentlich wenn

ansehnlichen Grundbeigenthum,

wunschenswerth erscheinen." (idem)
Si bien Savigny había descartado la idea de que el colonato fuera la continuación de antiguas costumbres, otros autores sí rastrearon esta institución en las primitivas relaciones sociales de la Roma republicana. Una de ellas, la clientela, suscitó la atención en 1833 de Christoph Schultz. Este autor sostenía que las fuentes confundían las figuras del liberto, del cliente y del colono, pero que en la realidad histórica se hallarían superpuestas, lo cual hablaría en favor de una cierta afinidad histórica entre estas instituciones (Schultz, 1833:341). Específicamente en relación al colono, Schultz sostuvo que se habría tratado originalmente de un cliente que trabajaba las tierras de su patrón de forma perpetua, incluyendo en esta relación a sus descendientes. Esta relación habría estado basada en la confianza mutua entre el patrón y su cliente-colono, hasta que la contractualización del acceso a la tierra transformó este vínculo de lealtad y dependencia personal en un vínculo legal indisoluble. ${ }^{38} \mathrm{Si}$ en la relación clientelar lo que primaba era la fide dominica, en la relación contractual era la mercede certa (ibidem: 351 ). Las idealizadas relaciones sociales primitivas romanas, no "corrompidas" todavía por la circulación del dinero y del derecho privado, suponían un nexo "natural" y "orgánico" entre el patrón y el cliente que se demostraba en el conocimiento mutuo e implícito, según Schultz, de las necesidades de cada parte, lo cual precisamente tornaba innecesaria la elaboración de un contrato. ${ }^{39}$ Todo eso cambiaría con el desarrollo del contrato de arrendamiento (locatio conductio), con el cual el colono ganaba independencia pero debía soportar también una mayor carga económica: el pago de una renta en dinero y el mantenimiento de las instalaciones y de todo el inventario de la granja, amén de las cláusulas sobre garantías en caso de incumplimiento. ${ }^{40}$ Esta nueva forma hizo deducir a Schultz un hecho fundamental: esta nueva relación debía producir una fragmentación de la propiedad terrateniente en una miríada de pequeños arrendatarios, debido a que un colono no tendría la capacidad económico de administrar una gran explotación. ${ }^{41}$ Así, una vez que el arrendamiento quedaba ligado a una determinada forma de gestión de la tierra, que suponía la fragmentación y autonomización de las operaciones agrícolas en manos de la unidad campesina, solo quedaba adjudicar esta condición a una tendencia particular de la historia de Roma. De ello se encargaría otro historiador alemán del derecho, Ernst Theodor Gaupp, al conectar al arrendamiento con el advenimiento del gran latifundio, supuestamente incompatible con una producción centralizada, ya que requeriría para ello tal cantidad de operarios esclavos que la empresa se tornaría antieconómica. ${ }^{42}$ Para Gaupp era una ley natural que el tamaño de la explotación suponía determinadas relaciones sociales y jurídicas. ${ }^{43}$ Resultaba clara entonces esta asociación entre la villa de tamaño medio y la esclavitud, por un lado, y el latifundio y el arrendamiento a colonos por el otro.

El siguiente y definitivo paso lo daría un discípulo de Savigny, Georg Friedrich Puchta, al retomar la segunda hipótesis que el viejo jurista alemán había formulado sobre el origen del colonato, la de la manumisión incompleta. Para ello, Puchta esbozó una relevante distinción entre el esclavo urbano y el rural. Para este autor, si bien la familia urbana gozaba de una vida menos esforzada que la familia rustica, ésta última tendría una mayor seguridad y estabilidad, debido a que resultaba imprescindible para el trabajo de la tierra. Al ser considerados una parte esencial de la tierra, el propietario no deseaba deshacerse de ellos y evitaba, salvo necesidad directa, su venta. Puchta sugería incluso que la condición real del esclavo rural era idéntica a la situación legal del colono bajoimperial. ${ }^{44}$ Pero entonces, ¿cuál sería la razón por la cual se sancionó una situación legal que ya existía de facto? Según Puchta, y aquí está la clave de muchas de las especulaciones que sobrevendrían luego, una manumisión limitada del esclavo, asentándolo en la tierra en calidad de colono, supondría beneficios económicos tangibles para ambas partes, colono y propietario, ya que el primero pondría más entusiasmo en su trabajo y el segundo vería acrecentados los ingresos de sus propiedades. ${ }^{45}$ Este estatus intermedio entre la esclavitud y la libertad se habría originado según Puchta mediante una ley supuestamente perdida que habría 
permitido este tipo de manumisión limitada. Esta teoría de la comparación de rentabilidades entre el sistema de trabajo del esclavo "en banda" y el del esclavo "instalado" tendría un largo y fructífero recorrido posterior.

La historiografía francesa recibiría con los brazos abiertos los avances de los eruditos alemanes. Charles Giraud, en su importante Histoire du droit français au moyen âge, sostenía que la clientela presentaba un estado análogo al del colonato, aunque creía al igual que Savigny que la esclavitud había reemplazado totalmente todo tipo de dependencia personal durante el intervalo de tiempo que separaba estas dos instituciones (Giraud, 1844: 149-150). Para Giraud, era a comienzos del período imperial cuando este nuevo sistema salió a la luz, espoleado por las necesidades de repoblar los campos de campesinos y de reducir la dureza de la esclavitud (ibidem: 157-190). Entre las fuentes de formación del colonato, el historiador francés colocaba en primer lugar la pauperización de la población libre italiana, que la condición de colono vendría a aliviar, al dejarle una cierta libertad personal y asegurarle su reproducción con una parte de la producción. El segundo grupo aportante al colonato serían los esclavos, cuya dura condición se habría visto atenuada debido a una creciente conciencia humanista entre los propietarios. ${ }^{46}$ En la misma línea de lo sostenido anteriormente por Puchta, Giraud concluía que esta forma era la más adecuada para incentivar el interés del colono sobre la producción y así generar un nuevo desarrollo productivo que la esclavitud había obstaculizado. ${ }^{47}$ Y del mismo modo que Gaupp, Giraud ubicaba al colonato en las peores tierras y principalmente en los grandes latifundios, que por no poder ser explotados en forma directa implicó que los agrónomos hablaran poco de él..$^{4}$

Hacia 1847 se producirá un giro en el debate sobre los orígenes del colonato. Si hasta ese momento habían prevalecido las teorías que adjudicaban su origen a la pervivencia de antiguas relaciones de servidumbre, a la instalación de bárbaros o a la manumisón de esclavos, a partir de los trabajos de Henri Wallon y de Karl Hegel el acento se pondrá sobre el rol del estado en la fijación de la población a la tierra, entendida como una medida eminentemente fiscal. Cabe destacar, sin embargo, que la noción del cambio de un sistema productivo agotado (esclavitud en cuadrilla) a un sistema renovador (colono doméstico) no resultó modificada. De esta forma el historiador Karl Hegel, hijo del filósofo, caracterizaba a la Roma bajoimperial como una sociedad subyugada por la presión del despotismo (Hegel, 1847: 86), que en aras de detener el proceso generalizado de decadencia económica acudió a la inmovilización de la población rural de la tierra. Eran los esclavos y principalmente los colonos, más productivos que aquellos, la base del poder tributario del Imperio. ${ }^{49}$ La justificación ya nos es conocida: al quedarse con una parte del producto, el colono ponía mayor interés que el esclavo en la producción. Pero Hegel agregaba un matiz más a esta argumentación: la suposición de que al transformar al esclavo en colono, el propietario se descargaba de los costos de manutención de la fuerza de trabajo a su servicio..$^{50}$ Idéntica explicación hallamos en la celebérrima Histoire de l'esclavage dans l'Antiquité de Wallon: la misma motivación económica de lucro que había motivado la explotación de masas de esclavos fue la que llevó al terrateniente a arrendar tierras a colonos libres por una parte de la producción, pues la mayor dedicación que el colono habría puesto en el cultivo de la tierra sería para el propietario más rentable que la vieja explotación esclavista. ${ }^{51}$ La detención de la expansión romana a partir del siglo I d. C. y la consiguiente crisis de aprovisionamiento de esclavos harían el resto (ibidem: 107-116). Para Wallon y Hegel, al igual que para toda la tradición anterior, el colonato surgía entonces como el sistema alternativo a la decadente villa esclavista. Charles Revillout daría forma final a la teoría de la "presión administrativa" al hacer hincapié primordialmente en el factor fiscal para explicar el surgimiento del colonato, pero manteniendo que la adopción de este sistema fue también una salida a los males ocasionados por la esclavitud. ${ }^{52}$
46. Giraud menciona a Plinio el Joven como un representante de esta tendencia: "Dans l'inflexible et barbare logique de l'aristocratie romaine, l'homme est réduit à nêtre plus qu'un outil, un instrument d'agriculture. Au temps des Pline, une réaction s'opérait; le travail de l'esclave, disait l'un d'eux, est un travail de désespoir et de malheur." (ibidem: 154-155).

47. “Mais Varron avait dejà conseillé l'usage de l'homme libre, par préference à l'esclave, ou bien de l'esclave à demi affranchi, de l'esclave intéressé à la prospérité du champ par un avantage actuel et par una garantie d'avenir. C'était une idée nouvelle dont l'application n'avait pas encore un grand développement." (ibidem: 155).

48. Aquí precisamente se encuentra in nuce la famosa distinción popularizada mucho después por Staerman entre propiedad territorial y extraterritorial, que correspondería cada cual a una forma de explotación distinta, la una intensiva y con esclavos (continúa en página 156)

49. "Ihre Steurkraft aber beruhte auf der Arbeit der Esclaven und hauptsätlich der Colonen, welche, weil sie selbst von dem gesteigerten Ertrage des Gutes Vorteil zogen, arbeitsamer waren als jene." (ibidem: 87).

50. “Ferner mochten sie Grundbesitzer es allerdings oft vorteilhafter finden, ihre landbauenden Esclaven, für deren Unterhalt sie selbst zu sorgen hatten, durch bedingte Freilassung in halbfreie Bauern zu verwandeln.", ídem.

51. "il y avait des circonstances où l'on croyait plus avantageux de préposer à son champ, non pas un intendant esclave, mais un colon intéressé à la culture par un partage des fruits. Ce fermier libre, dont Caton règle la part, et à qui Varron precrit des lois; ce fermier, que Caton recommande de renvoyer a l'expiration de son bail, et que Columelle, bien différent, voudrait y retenir par une hérédité volontaire, avec un sentiment plus vrai des intérêts de la culture;..." (Wallon, 1879: 104-105).

52. "On avait si bien, en effet, compris les inconvénients de la régie par les esclaves, que certain maîtres, au lieu d'avoir un vilicus, donnaient en ferme leur domaine à un serviteur de confiance qui ne travaillait plus pour leur compte (fide dominica), mais pour lui-même, et leur payait une redevance, comme aurait pu le faire un colon libre." (Revillout, 1856: 41746o, especialmente, 454-455). Sobre la teoría de la presión administrativa, véase (Clausing, 1925: 92-137). 
53. Serrigny da cuenta precisamente, como habíamos observado anteriormente, que se trataba de un descubrimiento de la economía política: "La exploitation pouvait se faire, soit en régie, c'est- $a$-dire directement pour le compte du maitre, et à ses risques et périls, soit à forfait. L'économie politique nous apprend que les hommes, et surtout les esclaves, qui travaillent pour le compte d'autrui, font peu d'efforts, et que leurs travaux sont peu productifs par le défaut d'interét personnel. Le travail à forfait est plus utile au maitre et plus lucratif pour l'ouvrier." (Serrigny, 1862: 393-394).

54. "Serrigny's ideas as to the sources of the free colonate were suggestive, but much work still remained to be done to show that there existed a small tenantry on the latifundia in sufficient numbers and widely enough distributed throughout the Empire to have formed the basis of the serf-coloni." (Clausing, 1925: 103).

55. "But no attempt had been made to relate the development of the colonate to general economic laws as set forth by the political economy of the day; and in this Rodbertus broke new ground." (ibidem: 104).

56. Este retorno a una economía natural se apreciaba en la renta en producto con la que el esclavo instalado tributaba al propietario: (continúa en página 156)

57. (Ibidem: 210-213). Rodbertus se apoyaba en el famoso rechazo del viejo Plinio a la utilización de esclavos encadenados. Las grandes extensiones de tierra del latifundio y su correspondiente gran cantidad de trabajadores esclavos necesarios impedirían supuestamente un control certero

de la producción, determinando de forma necesaria una tendencia hacia la Kleinwirtschaft:

"Zu der intensiven, ausgezeich-

neten römischen Culturmethode gehörte das unmittelbare Interesse

der Betreibenden selbst, daher

Theilnahme der besitzer und deshalb auch nur Kleinwirtschaft." (ibidem: 212-213). Hay que entender que Rodbertus criticaba las

teorías acerca de un supuesto agotamiento del suelo como explicación del colonato, cuando en realidad a sus ojos se estaba dando el proceso contrario, véase

la crítica a Dureau de la Malle sobre este aspecto, ídem, nota 7.

58. (Ibidem: 218-222). Rodbertus se basaba en la teoría de von Thünen sobre la localización de la producción agrícola, véase Thünen (1826).

\section{La formación definitiva del problema historiográfico de la transición del esclavismo al colonato en el debate Rodbertus- Heisterbergk}

En la década de 1860 la idea de la superioridad intrínseca del pequeño arrendatario por sobre el esclavo se había asentado firmemente. Así por lo menos lo declaraba en 1862 el jurista francés Denis Serrigny, al observar que, como ya lo había sugerido Puchta, los propietarios instalaron a sus esclavos rurales junto con sus familias para favorecer la productividad de la villa. ${ }^{53}$ Pero Serrigny consideraba que el esclavo instalado no era la única fuente de origen del colonato; solo explicaba las figuras jurídicas tardías del colono siervo o adscripticio, pero no podía explicar que en los códigos se hiciera referencia a colonos de condición libre, ingenui, que no eran esclavos del propietario pero sí "esclavos" de la tierra (ibidem: 390). Estos colonos libres eran, para Serrigny, ciudadanos sometidos voluntariamente a la autoridad de un propietario rico, libertos de baja condición o bárbaros dediticii, todas alternativas ya anteriormente delineadas. Pero lo importante de la postura de Serrigny era que al colocar a la población libre como el origen del colonato, generó toda una corriente de trabajos que buscaban demostrar y explicar la existencia previa de una gran cantidad de campesinos libres que trabajaban en los grandes latifundios como pequeños arrendatarios. ${ }^{54}$

Precisamente en este sentido tuvo una influencia determinante la publicación, en 1864, de la monografía del economista alemán Karl Johann Rodbertus sobre la cuestión del colonato. Rodbertus planteó el problema principalmente en términos de una transformación del sistema productivo dominante en el imperio romano, dando en cierta manera un comienzo formal al extendidísimo debate sobre la transición del esclavismo al feudalismo (entendido como sinónimo de colonato), y esbozando por primera vez una explicación de estos cambios basada en factores exclusivamente económicos. ${ }^{55} \mathrm{La}$ tesis principal de Rodbertus sostenía que en el siglo II d. C. la agricultura intensiva con esclavos había sido reemplazada por la parcelización de las grandes propiedades, convirtiendo de esta forma a los antiguos esclavos en siervos con pequeñas extensiones de tierra a su cargo. Se trataba del retorno a una "economía natural", a una economía del oikos que Rodbertus creía que había dominado durante toda la antigüedad. ${ }^{56}$ Una razón importante de este cambio era el agotamiento del mercado de esclavos debido al fin de las guerras de expansión, lo que obligó a instalar al esclavo y a favorecer su reproducción natural, formándose así una población servil hereditaria y de cierta forma "adscripta" a la villa (Rodbertus, loc. cit.).

Pero Rodbertus también añadió otras tres causas de índole interna al proceso de producción que justificaban la adopción de nuevas formas de explotación. En primer lugar una creciente especialización y sofisticación del proceso productivo, lo cual exigía mayores cuidados y una atenta supervisación de la parcela cultivada, tareas no aptas para ser hechas por cuadrillas de esclavos. ${ }^{57}$ En segundo lugar, un cambio en los patrones de consumo, principalmente de la ciudad de Roma, que implicaba la demanda de productos de huerta y avícolas, y que, según Rodbertus, desencadenó el cambio hacia la parcelización de la propiedad, forma más adecuada para la producción de los nuevos artículos demandados (ibidem: 213). El predominio de esta Kleinkultur o Parcellenwirtschaft se daba principalmente en Italia, que se convertía así en un hinterland agrícola de Roma, especializada en estos productos agrícolas más sofisticados, mientras que la producción de trigo se desplazaba hacia las provincias, donde seguiría dominando la Latifundienwirtschaft..$^{58}$ Por último, Rodbertus señalaba un problema de administración de las grandes propiedades. El arrendamiento de un latifundio a un colono libre no hubiera solucionado el problema, ya que éste habría utilizado también una familia de esclavos para explotarlo. Por lo cual la única opción era subdividir el latifundio y arrendarlo a pequeños arrendatarios que trabajaran 
directamente la tierra (Rodbertus, 1864: 222). En última instancia esto significaba el retorno a la economía natural del oikos, que se había visto interrumpida por el fenómeno anormal de la gran afluencia de esclavos a bajo precio a la península itálica, pero una vez que estas condiciones excepcionales tuvieron necesariamente que finalizar (por el fin de las guerras de conquista), la situación habría vuelto a la normalidad de la pequeña economía campesina. ${ }^{59}$

Una vez dilucidada la necesidad económica de un cambio de sistema, quedaba el problema acerca de cuál sería el origen de esta clase de pequeños arrendatarios. Al igual que Puchta, Rodbertus consideraba que la nueva clase de los colonos estaba conformada por esclavos instalados, aunque no creía que hubiera sido necesario una manumisión para que este asentamiento se produjera. La recomendación de Columela acerca de exigir más trabajos que rentas a los colonos era un indicio para Rodbertus de una relación de dependencia servil. Fortalecía esta convicción con los reiterados casos en el Digesto de servi quasi coloni, y con la suposición de que los colonos de Plinio el Joven trabajaban pequeñas explotaciones y eran, en realidad, esclavos instalados (ibidem: 225). Junto a estos colonos esclavos también existirían colonos adscripticii, quienes fungirían como prendas inseparables de tierras que estuvieran como garantía de una deuda. Las reformas de Diocleciano habrían unificado la condición de los colonos esclavos y la de los adscripticios, al mismo tiempo que convertían en un rasgo general la adscripción al suelo con el objeto de asegurar el cobro de los impuestos (ibidem: 240-241). Respecto al problema de explicar el origen del colono de condición libre, Rodbertus lo zanjaba al considerar que los colonos libres eran colonos esclavos que habían sido manumitidos, pero que naturalmente el acto de manumisión no implicaba que pudieran abandonar la tierra, ya que estaban ligados a ella por ley y no por su antigua condición servil.

Resulta difícil exagerar la importancia de la tesis de Rodbertus. A partir de él las argumentaciones sobre el desarrollo del arrendamiento y del colonato adquirieron una naturaleza estrictamente económica, lo que permitiría ampliar una discusión que había permanecido básicamente en los cauces jurídicos desde sus orígenes. ${ }^{60}$ Por ello, el principal oponente a las tesis de Rodbertus en aquel momento, Bernhard Heisterbergk, contrapuso una argumentación basada también en causas económicas. Heisterbergk sostuvo que no había ninguna evidencia en la península itálica de este supuesto retorno a la pequeña explotación (Heisterbergk, 1876: 43), y que además, las paupérrimas condiciones económicas del campesinado independiente, en crisis demográfica desde finales de la República, habrían constituído un obstáculo insuperable para el desarrollo de aquella economía hortícola supuesta por Rodbertus (ibidem: 44) ${ }^{61}$ A su vez, mientras que Rodbertus adjudicaba mayormente a la población servil instalada el núcleo originario del colonato, Heisterbergk señalaba que la cantidad de esclavos no debía ser tampoco muy numerosa, debido al recurrente argumento del desabastecimiento de esclavos por el fin de las guerras de expansión, y también por las pérdidas ocasionadas por las revueltas anti-esclavistas (ibidem: 53). Por todos estos motivos, Heisterbergk colocaba el origen del colonato en las provincias, no en Italia, y para justificar esta postura recurría a una original argumentación basada en los efectos económicos de la tributación imperial (ibidem: 68). A ojos de Heristerbergk, la principal diferencia entre Italia y las provincias era que la primera, al estar libre de impuestos, generaba una economía latifundista suntuaria e improductiva, ${ }^{62}$ mientras que en las segundas, al estar sujetas a tributos, se habría alentado un uso más eficiente e intensivo de la tierra, en base a la parcelización de los latifundios y a su explotación por una extensa clase de pequeños arrendatarios. ${ }^{63}$ Esta clase estaría constituída por la población local de las provincias, cuya condición dependiente y hereditaria los romanos la habrían heredado de las antiguas formas estatales dominantes (Egipto), o habría sido alentada por ellos mismos (Africa) (ibidem: 81). Si el colonato se había formado originalmente en las provincias bajo el impulso de
59. “Allein die landwirtschaftliche Culturart, Reihensaat und Handhackbau, bestand doch von jeher, und es ist daher in der That eher zu verwundern, dass die Römer dennoch zu jener Wirtschaft übergehen konnten, als dass sie sich bald wieder von ihr zu trennen suchte. (..) Wahrscheinlicher ist, dass der niedrige Wert, den gewöhnliche Landbausclaven in Folge der grossen Eroberungen in den beiden letzten Jahrhunderten v. Chr. jedenfalls haben mussten, es damals in der That weniger unökonomisch machte, dem aus andern Gründen um dieselbe Zeit sich ausbreitenden Latifundien besitz auch noch die Latifundienwirthschaft hinzuzufügen." (ibidem: 223).

6o. Hallamos la misma idea en Marx y Engels, influenciados sin duda por el estudio de Rodbertus: "Die auf Sklavenarbeit gegründete Latifundienwirtschaft rentierte sich nicht mehr; sie war aber damals die einzig mögliche Form der großen Agrikultur.

(continúa en página 156)

61. Heisterbergk también señalaba que la teoría de von Thünen difícilmente pudiera aplicarse a Italia debido al terreno montañoso de ésta y a la lentitud, general en el mundo antiguo, del transporte por tierra, lo que posibilitaba que la producción de las provincias mediterráneas del imperio tuvieran mejor acceso al mercado de Roma que las regionas itálicas más alejadas, ibidem, pp. 56-59.

62. Heisterbergk recurre a una clásica caracterización del terrateniente romano como un rentier, desinteresado en las tareas productivas: "Ein Blick auf die subjectiven Motive der Latifundienbildung im römischen Reiche wird dieser Tatsache noch schärfere Umrisse geben. Diese Motive waren nicht wirtschaftlicher Natur, sie waren nicht auf Vernehrung des Ertrages, nicht auf Ausbeutung sondern nur auf Ausbreitung des Besitzstandes gerichtet; Stolz, Uebermuth, Herrschsucht, militärische, nicht kaufmännische Leidenschaften waren die Triebfedern;" (ibidem: 67).

63. En este aspecto Heisterbergk coincidía con Rodbertus en que una explotación intensiva de la tierra requería necesariamente de la pequeña producción, con lo cual la gran explotación esclavista quedaba descartada como una opción disponible para los propietarios en las provincias: “Wenn die Steuerplifchtigkeit des Bodens den Grossgrundherrn das freie (continúa en página 156) 
64. Principalmente Keith Hopkins y su modelo de comercialización forzada, el imperio tributario de Peter Bang y el estado fiscal tardorromano (cuya base precisamente es el colono arrendatario) de Chris Whickham.

65. Aparentemente, sin conexión entre ellos (Finley, 1982: 185).

66. La tierra los retiene "non pas encore à titre de colons, mais à titre de débiteurs." (Fustel De Coulanges, 1885: 18). En referencia a las condiciones draconianas de los contratos de arrendamiento, Weber señalaba: "es ist jedenfalls das sicher, dass ein sozial bedeutsamer und selbstbewusster Stand sich einen solchen Rechtszustand nicht hätte gefallen lassen" (Weber, 1891: 232).

67. En su trabajo L'alleu et le domaine rural, que forma parte de su monumental Histoire des institutions politiques de l'ancienne France,

Fustel rastreaba los orígenes del dominio señorial en la villa romana. (continúa en página 157)

68. Da cuenta de ello Finley, al jactarse de haber rescatado del olvido las tesis de Fustel (Finley, 1982: 185-186).

69. "The economy of plantations that needed many slaves was not as succesful as the economy of small plots for which free workers and free tenants were increasingly used, at first perhaps because the numbers of the slaves sank (Pliny, Letters, III, 19),

then also because they were more efficient." (Neurath, 2005: 143).

70. "The compulsory methods were not entirely rejected, and the margin of personal authority over the serf by no mens got rid of. But the emphasis came to lay on the conciliation of labourers by a direct and personal share in the cultivation of the land: it was

not a question of humanity or even

of best policy -it became a question of necessity in face of the great crisis threatened the political existence of the Empire as well as the continuance

of its economic basis- the cultivation of the land." (Vinogradoff, 1905: 77). la fiscalidad, las reformas de Diocleciano, al transformar el suelo italiano en tierra también tributable, supusieron la introducción del colonato en Italia. La condición indispensable del colonato era siempre la misma: el peso de la tributación imperial, que genera un impulso hacia la intensificación de la producción. Si bien Heisterbergk disentía de Rodbertus en el origen geográfico del colonato, había algo en lo que coincidía absolutamente, y era el hecho de ver en la pequeña producción, esto es, en la parcelización del latifundio y su cesión en arriendo a pequeños productores, una forma intrínsecamente más productiva que el viejo latifundio esclavista, cuya existencia debía más a la ostentación suntuaria que a una razón económica. Además, puede considerarse la teoría de Heisterbergk como la iniciadora de toda la corriente contemporánea que subraya especialmente el papel de la tributación estatal como el motor de la actividad económica. ${ }^{64}$

\section{La persistencia del debate en la historiografía del siglo XX}

Cabe destacar la aparición en este debate de una postura alternativa que no interpretó que la esclavitud y el arrendamiento fueran sistemas antagónicos (mucho menos que el segundo fuese más productivo que el primero), sino que entendía la organización de la villa como un complejo organismo que conjugaba distintos tipos de relaciones laborales. Nos referimos a Fustel de Coulanges y a Max Weber, quienes desarrollaron en paralelo posturas ciertamente afines. ${ }^{65}$ Ambos autores cuestionaron la teoría de la "presión administrativa" al señalar que el colonato fue más una consecuencia de la decadencia económico-social del campesinado, principalmente por el problema del endeudamiento, que una decisión "desde arriba". ${ }^{66}$ Ambos autores también hicieron importantes análisis sobre la complementariedad del trabajo de los colonos en el funcionamiento de la villa esclavista. En base a la revolución que significó el descubrimiento de las inscripciones norafricanas, que mostraban el funcionamiento de propiedades imperiales del siglo II d. C. como centros de producción cuya fuerza laboral estaba compuesta por esclavos y colonos obligados a la prestación de servicios laborales, tanto Fustel como Weber creyeron ver aquí los orígenes del señorío medieval. ${ }^{67}$ Más allá de que esta visión resultara desacertada, se puso por primera vez aquí una noción más compleja acerca del funcionamiento práctico de las explotaciones rurales orientadas al mercado, acercándose a lo que podríamos denominar como una "logic of deployment" (Banaji, 1992: 379-391).

Sin embargo, las innovadoras posturas de Fustel y de Weber pronto quedaron relegadas al olvido. ${ }^{68}$ Otto Neurath, sociólogo alemán contemporáneo a Weber, consideraba que el desarrollo comercial era incompatible con la economía esclavista debido a la poca flexibilidad de la plantación frente a los vaivenes de los ciclos comerciales. En este sentido la utilización de trabajo libre, básicamente mediante la contratación de campesinos sin tierras, le permitiría al propietario desprenderse de ellos cuando las ventas cayesen, o contratar más en caso contrario. Por ende la plantación esclavista fue reemplazada por el cultivo a pequeña escala, más racional y eficiente, fenómeno que Neurath deducía de las epístolas de Plinio el Joven, convertidas ya a esta altura en la "prueba" definitiva del cambio del modo de producción. ${ }^{69}$ Otros autores plantearon la progresividad del colonato en función de una supuesta infertilidad creciente de la agricultura. Fue el caso del medievalista ruso Paul Vinogradoff, quien sostenía que el objetivo de esta relación era el mejoraramiento de las condiciones agrícolas mediante la conciliación entre el trabajador y los medios de producción. ${ }^{70}$ Esta postura significaba enfatizar no tanto los rasgos compulsivos de la institución sino el estado acuciante de la agricultura romana de la época imperial, que ocasionaba el abandono de las tierras por la desesperación del campesino. No era entonces la coerción lo que generaba las condiciones de un crecimiento económico sustentable, sino lo que 
Vinogradoff denominaba el "self-government" de los pequeños productores, ya que supuestamente el rendimiento debía de aumentar si los productores directos poseían el control de la explotación. ${ }^{71}$

También el primitivismo de Rodbertus fue recuperado a la hora de explicar el fin de la esclavitud y los orígenes del colonato, como sucedió con el libro de Giuseppe Salvioli, Le capitalisme dans le monde antique. Para Salvioli, la supervivencia de la pequeña propiedad campesina era el producto de una tendencia económica objetiva, mucho más fuerte que cualquier tipo de violencia que pudieran ejercer los grandes terratenientes sobre ella. En la clase de los pequeños propietarios se hallaba una base estable, correspondiente a una sistema económico que presentaba pocas oportunidades para el aprovechamiento de economías de escala, debido a las deficiencias del transporte y a la escasa integración de los mercados. ${ }^{72}$ El latifundio esclavista era una economía cerrada, escasamente relacionada con los mercados y de explotación extensiva, cuyo principal objetivo era el autoconsumo (ibidem: 191). ${ }^{73} \mathrm{~A}$ su vez, era en la clase de los pequeños y medianos propietarios, a la cual se refería Salvioli como la burguesía del mundo romano, donde se encontraba generalizado el sistema del colonato. Estos pequeños propietarios harían cultivar sus pocas tierras por medio de contratos de aparcería a colonos, obteniendo rentas suficientes para llevar una vida digna en la ciudad. Salvioli señalaba que este sistema era el más adecuado a la pequeña propiedad (ibidem: 103), una derivación de su visión bastante pesimista sobre los rendimientos agrícolas en Italia (ibidem: 182). Años más tarde Ferdinand Lot repetiría los mismos conceptos de Salvioli en La fin du monde antique et le début du Moyen Âge, de 1927. Allí Lot colocaba al arrendamiento de tierras como un fenómeno característico de la regresión económica del mundo romano, pues este sistema sería "lo más contrario que existe al sistema de una explotación en régimen capitalista" (Lot, 1956: 70). ${ }^{74}$ Otros autores repitieron los mismos lugares comunes acerca de la conveniencia del sistema de arrendamiento, sea por su mayor productividad, por ajustarse mejor a una economía de intercambios escasos o por las inclinaciones absentistas de los propietarios. En su influyente Agricola, W. E. Heitland consideraba que el latifundio esclavista había sido un sistema nocivo para el desarrollo agrícola romano. El razonamiento ya nos es conocido: el trabajo del esclavo era menos productivo que el del campesino libre, ya que el primero no tendría el incentivo de poder mejorar su situación, trabajando por ende de forma descuidada. ${ }^{75}$ Pero el fracaso económico de la gran propiedad no produciría una reversión al sistema de la pequeña propiedad, sino que incentivaría el arrendamiento a colonos. Esto le permitía al propietario vivir en la ciudad de las rentas que obtenía, caracterizándose esta transformación como el cambio de una agricultura basada en la propiedad hacia otra basada en el arrendamiento. ${ }^{76} \mathrm{~A}$ pesar de que en su momento la gran propiedad esclavista había desplazado al antiguo yeoman romano del campo, ambos sistemas para Heitland eran esencialmente iguales ya que se basaban en el cultivo directo a cuenta del propietario, sea por él mismo o a través de una cuadrilla de esclavos. Ahora, en cambio, predominaba la administración indirecta y la delegación de responsabilidades en el colono libre, quien supuestamente prevendría el robo y el desperdicio que ocasionaba el trabajo de los esclavos. En la misma época, el historiador norteamericano Tenney Frank criticó ásperamente los planteos de Fustel y Weber sobre una posible complementariedad entre la villa esclavista y los colonos, considerándolos más bien como dos sistemas alternativos de administración a los cuales podía recurrir el propietario (Frank, 2004 [1927]). El autor consideraba que la villa del siglo I d. C. era autosuficiente en mano de obra (ibidem: 175) y descartaba al mismo tiempo la idea de una "scientific agriculture", al no suponer la plantación esclavista un aumento de la productividad. ${ }^{77}$ Frank consideraba que en realidad había sido el temor a los esclavos, luego de los levantamientos serviles del último siglo de la república, lo que ocasionó el desarrollo del arrendamiento. Los colonos habrían sido principalmente pequeños campesinos que trabajaban la tierra con mano de obra familiar en tierras arables y cuya
71. "And in this connection arose another great movement: by side of the growth of political patronage in favour of the great goes the growth of economic self-government in favour of the small. I use the expression "selfgovernment" on purpose, because not independence, but a power of directing efforts and seeking profits by the energy and insight of the labourers themselves, rather than by management from above, appears as the only anchor of safety in this time of great difficulties." (ibidem: 74).

72. "Non seulement en Italie, mais dans les provinces et même en Afrique (Aggenus Urb., 85), il y avait una classe assez importante, un peuple de petits propiétaires, de plébéiens, de cultivateurs libres, qui sinon à Rome, certaneiment dans les autres parties de l'Empire, formaient l'élément le plus important de l'économie. On ne peut rien expliquer de la vie de l'antiquité romaine si on n'admet pas l'existence de cette classe, qui forme le noyau économique et politique des villes et des campagnes." (Salvioli, 1906: 109).

73. Para una crítica de los supuestos primitivistas de Salvioli, cf. Banaji y Tedesco (2017: 145-156).

74. Lot caracterizaba al capitalismo como un "régimen en el cual todas las fuerzas de la sociedad tienden a la producción de valores que se vierten en mercados cada vez más extendidos" (idem: 52). Si bien Lot hacía uso de la distinción entre "economía monetaria"

(continúa en página 147)

75. "When we admit that slavelabour is wasteful, we mean that its output as compared with that of the free labour is not proporcionate to the time spent" (Heitland, 1921: 157).

76. “The most valuable part of this paper is its recognition of the vital change in Italian agricultu$r$, the transfer of farming from a basis of ownership to one of tenancy." (ibidem: 297).

77. De hecho los propietarios preferirían a los colonos que a los esclavos: "It must also be noted that the growth of imperial estates could hardly have resulted in greater productiveness. Ordinarily the substitution of free peasant renters for slave labor seemed to Pliny and Columella desirable, provided the owner watched his property. To speak of capitalistic farming with slave labor as "scientific agriculture" is a modern nuance not excused by our sources." (ibidem: 223). 
78. "This system required less of an initial outlay, less supervision and assured a more interested attention to the land. But it must not be supposed that the system brought back Italy's vanishing native stock, since farm slaves were often set free to become freed-men tenants." (ibidem: 186).

79. Observación similar en cierto sentido a la que había formulado Schultz.

80. "As the plan and the distribution of rooms in the farms agree closely with the descriptions of both Varro and Columella, it is clear that they were managed according to the scientific manuals on agriculture and that the labour employed was the labour of the slaves. There was hardly room on them for the peasant plots of the coloni of Horace. The Campanian farms were entirely capitalist, with no survivals of the peasant economy of the past." (ibidem: 63). producción principal era el trigo (ibidem: 215). Este sistema incluso tendría las ventajas de un menor desembolso de capital inicial, una menor supervisión y, por supuesto, un mayor interés en el cuidado de la tierra por parte del colono. ${ }^{78}$ Como vemos, nuevamente el leit-motiv del interés personal del arrendatario en la producción. No obstante, teniendo en cuenta los problemas que ocasionaban los procedimientos judiciales hereditarios en lo que respecta al instrumentum de las explotaciones agrícolas, de lo cual los juristas temprano-imperiales daban debida cuenta, Frank señalaba agudamente que no debería de haber sido una operación sencilla distribuir entre un número grande de arrendatarios una villa equipada para funcionar como una unidad (ibidem: 178$) .79$

Si bien los escritos de Tenney Frank habían formulado algunas dudas interesantes sobre la efectiva plausibilidad de una transición directa de la villa esclavista al colonato, la aparición de la obra de Mijaíl Rostovtzeff cerró definitivamente esta posible línea de investigación al retomar de nuevo la vieja problemática, aunque dotándola de un enfoque novedoso cuyo impacto sería muy grande en las sucesivas generaciones de historiadores. La contraposición entre dos modelos alternativos de producción, el esclavista y el basado en colonos, fue mantenida en su esencia por Rostovtzeff, aunque con algunas diferencias remarcables. Rostovtzeff consideraba al arrendamiento una continuación de la economía campesina de subsistencia, producto del descenso social de los antiguos pequeños propietarios de la Italia central que perdieron sus tierras con la expansión del latifundio y pasaron a ser colonos de los capitalistas romanos y municipales (Rostovtzeff, 1958: 22-23). En contraposición a la economía de subsistencia del colono, se alzaba la granja capitalista y su forma científica de cultivo, que producía para la venta y era explotada con esclavos. Era claro para Rostovtzeff que ambos modelos eran incompatibles, debido a que las explotaciones esclavistas eran más eficientes en la competencia. ${ }^{80}$ Con el progresivo desarrollo económico de las provincias, la economía esclavista de Italia central entraría en crisis. La producción de vino y aceite, productos principales de la agricultura científica, vio sus cuotas de mercado disminuidas por la importación de estos artículos desde las provincias, ante lo cual se produjo un desplazamiento hacia el arrendamiento a pequeños colonos que cultivaban principalmente trigo. De esta forma los propietarios habrían optado por contentarse con una renta pequeña, pero segura, como consecuencia de las condiciones desfavorables del mercado (ibidem: 98-101).

En el esquema de Rostovtzeff la agricultura científica y el arrendamiento operaban entonces como dos alternativas contrapuestas. Mientras que la primera significaba una inversión genuinamente capitalista, solo posible en las propiedades de tamaño medio que recomendaba Columela, la segunda significaba el triunfo de una mentalidad de rentiers, ajena a las innovaciones productivas, y propia del latifundismo. Por ello Rostovtzeff era contundente al afirmar que el arrendamiento de tierras fue lo que acabó con la agricultura científica en Italia (ibidem: 203). Sin embargo, hay que señalar que jamás a Rostovtzeff se le ocurrió sugerir que el arrendamiento pudiera ser más rentable que la explotación directa con esclavos. La crisis de esta última forma se debía, como ya se dijo, a la competencia de otras regiones del imperio cuya forma de producción se supone que era esclavista, y también a una opción de retiro del terrateniente del control de la producción, que estaba dispuesto a aceptar un menor ingreso de sus propiedades a cambio de un mayor otium.

No obstante, la idea de la superioridad productiva del pequeño arrendamiento como sistema de producción volvió a adquirir un renovado vigor con la publicación del importantísimo trabajo de Marc Bloch sobre la transición del esclavismo al feudalismo (Bloch, 1947: 30-44). Bloch señalaba que al producirse la crisis de la esclavitud en el imperio por el final de las guerras de expansión imperial, los propietarios recurrieron al régimen de la tenencia (tenure), ya conocido por los germanos, en el cual los 
antiguos esclavos pasaban a ser arrendatarios en parcelas individuales cedidas por el amo. ${ }^{81}$ La causa de este cambio se debía según Bloch a una cierta comparación de rentabilidades entre el uso del "ganado humano", a la vieja usanza de los romanos, y la colocación de estos esclavos como terrazgueros. La segunda opción habría sido la más rentable debido a los inconvenientes de la primera, como el alto precio del esclavo y las consecuencias que su uso acarreaba, como la inmovilización del capital o el bajo nivel productivo. El esclavo-arrendatario, por el contrario, desarrollaría una mayor productividad y tendría mejores perspectivas de reproducción debido a la seguridad que le brindaba su pequeña tenencia. ${ }^{82}$

\section{La historiografía soviética}

En el ámbito de la historiografía soviética podemos observar uno de los desarrollos más interesantes del debate sobre la transición. Este interés se debe no tanto a una originalidad del enfoque, ya que básicamente se mantendrá la noción del cambio de un sistema agotado por otro renovador, sino por la justificación que se hará de este cambio. Apelando a las leyes del "materialismo dialéctico" de Marx y Engels, la representante más destacada de la escuela soviética, Elena Staerman, buscó brindar una explicación estrictamente materialista de la transición, entendida como el esclarecimiento de la forma de actuación de la "ley de correspondencia necesaria entre las relaciones de producción y el carácter de las fuerzas productivas" (Staerman, 1989: 66). Este enfoque suponía alejarse de una visión solamente basada en la violencia de la lucha de clases (interpretación que el estalinismo había impuesto) para acentuar en cambio las fuerzas económicas que actuaban por debajo de la superficie del conflicto político, y que al mismo tiempo lo determinaban. ${ }^{83}$ La conclusión a la que llegaba Staerman era que la clase objetivamente progresista, portadora de nuevas relaciones sociales de producción, no era la de los esclavos y las demás clases explotadas sino la de una incipiente aristocracia terrateniente feudal que, en el siglo III d. C., desplazó a la antigua clase propietaria esclavista y reemplazó la explotación de esclavos por la de colonos. Esta transformación obedecía a las contradicciones internas del régimen esclavista, que se demostraba incapaz de continuar el desarrollo de las fuerzas productivas y que por lo tanto debía ceder su lugar a las nuevas relaciones de producción basadas en el trabajo servil, adecuadas al nivel de desarrollo que las fuerzas productivas habían alcanzado. ${ }^{84}$

Staerman comenzaba por identificar cuatro formas de propiedad en la historia romana: la esclavista, la comunal, la latifundista (o extra-territorial) y la imperial (o estatal) (Schtajerman, 1964: 26). Prácticamente extinta la forma comunal hacia finales de la república y siendo la forma imperial-estatal casi una variante de la latifundista, el foco recaerá entre esta última forma y la esclavista, entendidas como dos formas antagónicas. El modo de producción esclavista, basado en la plena propiedad sobre el productor (esclavo) y en la limitada propiedad sobre la tierra (explotaciones de pequeña y mediana extensión, villae de tipo catonianas), estaría ligado esencialmente a la producción para el mercado y a una cierta explotación racional de la mano de obra, caracterizada por la especialización y la división del trabajo a un nivel de cooperación simple. ${ }^{85}$ La crisis de este régimen estaría marcada por sus contradicciones internas. Staerman descartó las teorías que explicaban la crisis de la esclavitud por factores exógenos, como aquellas que señalaban la dificultad del aprovisionamiento de esclavos por el cese de las guerras de conquista (Weber) (ibidem: 8), o las que suponían una crisis de rentabilidad para las explotaciones esclavistas italianas por la competencia de la producción de las provincias occidentales (Rostovtzeff). ${ }^{86}$ En lugar de ello apuntó a dos fenómenos interrelacionados que condenaban a la esclavitud a su desaparición: el primero, su conservadurismo técnico, lo que imposibilitaba
81. Bloch incluso se acercaba bastante a la formulación de Weber acerca de la relación de arrendamiento como forma encubierta de una relación laboral: “lls continuaient à peiner pour le maître; mais ils nétaient plus entretenus par lui, pas plus qu'un patron, aujourd'hui, n'entretient ses ouvriers; la terre qui leur avait été cédée - soumise en outre à des redevances, qui ne nous importent pas ici - était comme leur salaire, dont ils devaient vivre." (ibidem: 34$)$. El colonato sería un reco nocimiento legal de esta situación.

82. Ídem. Esta idea tendrá mucha influencia en la historiografía medieval. Georges Duby repetía prácticamente el mismo argumento de Bloch para explicar la generalización de relaciones serviles durante la temprana Edad Media: “L'apparition et la multiplication des tenures paysannes au viie siècle sont donc également la conséquence (continúa en página 157)

83. Refiriéndose a la historiografía soviética, representada claramente en la figura de Kovaliov, Staerman señalaba “que no se tenía en cuenta la correlación entre las fuerzas productivas y las relaciones de producción, y se estudiaba la historia de la lucha de clases fuera de esa correlación." (idem).

84. En 1957 Staerman publicó su tesis de doctorado sobre la crisis del siglo III y el cambio del modo de producción (tomamos como referencia la traducción alemana): Schtajerman, E. M., Die Krise der Sklavenhalterordnung im Westen des römischen Reiches, Berlín, 1964. Finley, nada afecto a la historiografía marxista soviética, reconocía no obstante que era la "más seria investigación estructural de amplio alcance" sobre el tema, véase Finley (1982: 176).

85. “Die Entwicklung der Warenproduktion war untrennbar mit der Entwicklung der Sklavenhalterwirtschaft verbunden" (ibidem: 35).

86. Staerman señala que la teoría de Rostovtzeff "fue acogida por numerosos historiadores soviéticos", en referencia clara a Kovaliov (Staerman y Trofimova, 1979: 8). Sin embargo, su noción de la explotación esclavista de tamaño medio como forma económica más dinámica que el gran latifundio servil debía mucho a Rostovtzeff. Aquí vale lo ya señalado por Fernández Ubiña acerca de las grandes coincidencias entre las interpretaciones marxistas y las "burguesas", reconocidas abiertamente por los historiadores antes de 1917 pero ocultas luego de esta fecha a causa de la confrontación ideológica entre occidente y la URSS, véase Fernández Ubiña (1982: 49-50). 
87. "Eine Villa konnte nicht über bestimmte, recht enge Grenzen hinauswachsen, da die Organisation vieler Sklaven und die Aufsicht über sie schwierig war." (Schtajerman, 1964: 91).

88. Staerman se hace eco aquí de las condiciones necesarias que establece Marx para la generalización del uso de la moneda: “Bei gewissem Höhegrad und Umfang der Waarenproduktion greift die Funktion des Geldes als Zahlungsmittel über

die Sphäre der Waarencirkulation hinaus. Es wird die allgemeine Waare der Kontrakte. Renten,

Steuern u.s.w. verwandeln sich aus Naturallieferungen in Geldzahlungen. Wie sehr diese Umwandlung durch die Gesammtgestalt des Produktionsprocesses bedingt wird, beweist z.B. der zweimal gescheiterte Versuch des römischen Kaiserreichs alle Abgaben in Geld zu erheben." (Marx, 1987: 160-161).

89. En esto Staerman seguía la interpretación de Gummerus por sobre la de Weber.

90. “Wenn man jedoch einem Latifundium immer neue Parzellen mit neuen Kolonen hinzufügte, konnte man es ins Unendliche vergrö ern; sein Besitzer brauchte sie nicht um die Arbeitsorganisation zu bemühen, erhielt vielmehr immer neue

Einkünfte durch die Zahlungen der Kolonen." (Schtajerman, 1964: 91). la reproducción ampliada del sistema (Staerman, 1989: 85). Al no haber ningún estímulo para el esclavo trabajador, éste no realizaba su trabajo de forma correcta. Además tampoco los esclavos podrían ser explotados intensivamente debido al temor de una revuelta. Al no ser posible una reproducción intensiva, tampoco la extensiva era una alternativa debido a que una propiedad de grandes extensiones ocasionaba altos costos de vigilancia sobre la mano de obra. ${ }^{87} \mathrm{El}$ segundo factor, y al mismo tiempo consecuencia del primero, sería la creciente contradicción entre esta base económica natural y el amplio desarrollo monetario que había alcanzado la economía romana (ibidem: $78-79) .{ }^{88}$ Ante ello, una nueva forma de producción surgida en las provincias occidentales se impondría como alternativa al impasse económico generado por la esclavitud: el gran latifundio del modo de producción feudal, basado en la limitada propiedad sobre el productor (colono, siervo) y en una menos limitada propiedad de la tierra (gran propiedad terrateniente) (Staerman, 1989: 70-73).

Está claro que en la reconstrucción histórica del proceso de transición elaborado por Staerman, a la figura del esclavo se le contrapone la del campesino o colono arrendatario. Durante el período de florecimiento de las relaciones esclavistas, Staerman señalaba que los colonos eran el complemento necesario de las haciendas, con independencia de su tamaño, como lo atestiguaba el caso de las fincas de Horacio. No obstante, la autora negaba enfáticamente cualquier rol de los colonos en el proceso productivo de las tierras que no hubiesen sido puestas en arriendo (Staerman y Trofimova, 1979: 40) ${ }^{89}$ Solo a partir del siglo II y como consecuencia de la crisis de la esclavitud el arrendamiento pasaría a ser un "componente orgánico" de las grandes propiedades. Desde el punto de vista productivo, no obstante, es claro que Staerman consideraba al sistema del colonato o del arrendamiento como una forma "menos coactiva" y más progresista que la esclavitud ya que el arrendatario, a diferencia del esclavo, tendría un incentivo personal en el trabajo de la tierra, al tener el control del proceso de producción (ibidem: 79). Al mismo tiempo, el propietario se liberaba de las tareas de supervisión y se conformaba con la percepción de rentas..$^{90}$ Como se puede observar, incluso desde una óptica marxista ortodoxa el viejo esquema del interés del productor en la producción como motor del progreso se mantenía intacto.

Los desarrollos teóricos soviéticos tuvieron eco en el mundo occidental. El historiador marxista italiano Santo Mazzarino elaboró un relato muy parecido al de Staerman en su obra de 1959, La fine del mondo antico. Allí Mazzarino abordó críticamente la teoría de Weber sobre la decadencia del mundo antiguo, objetando el desmedido énfasis qué el sociólogo alemán había colocado en el fin de las guerras de conquista como supuesta causa de la crisis de la esclavitud. En lugar de ello, Mazzarino sostuvo que el sistema esclavista no era redituable debido a que el esclavo "sin familia" de los barracones no estaba motivado en el trabajo, mientras que aquel que pudiera instalarse con su familia y su peculio trabajaría de forma más productiva. Con ello el historiador italiano agregaba que con el reemplazo del esclavo por el colono se volvía a la forma itálica tradicional del pequeño cultivo, ya sea con siervos o con arrendatarios libres, que había existido desde los tiempos del dominio etrusco y que solo durante un paréntesis histórico había sido reemplazado por la plantación esclavista importada desde Cartago (Mazzarino, 1961: 151-154).

\section{La historiografía actual: balance y perspectivas}

Como ya hemos tenido ocasión de comprobar, la teoría de Domenico Vera no es en absoluto original. Los trabajos de Staerman y Mazzarino constituyen su precedente inmediato: la "economia drogata" es el "paréntesis cartaginés" de Mazzarino; la incompatibilidad de la esclavitud con las formas de propiedad "extraterritoriales" o 
latifundísticas, que habrían obligado a los grandes propietarios a plegarse al arrendamiento, es en esencia la teoría de Staerman..$^{91}$ Incluso la idea de Staerman acerca de la insostenibilidad de la economía comercial y dineraria, asociada a la explotación esclavista, y el repliegue por ende a formas de "economía campesina" (en otro tiempo se hubiera dicho "economía natural"), encajan plenamente con la teoría de la excepcionalidad de la economía mercantil mediterránea de Vera. A su vez, la teoría de Staerman, posiblemente la más desarrollada de todos los historiadores del siglo XX que abordaron este tema, bebía de los desarrollos historiográficos del siglo XIX que hemos analizado al principio. En este sentido, resulta llamativo que el artículo de Vera se presentara como una "crítica" de la teoría de Moses Finley sobre la crisis de la esclavitud, y ni siquiera pueda reparar en las muy acertadas debilidades que marcó Finley en la teoría de Staerman (y que se aplican enteramente a Vera). La más obvia de ellas es la insostenible idea de que el gran latifundio territorial sea incompatible con la esclavitud. Finley señala, con toda razón, que los latifundios solían dividirse en unidades más pequeñas que eran explotadas por trabajo esclavo, posibilidad que Staerman en ningún momento contempla (y mucho menos Vera) (Finley, 1982: 177)..$^{92}$ ¿Y qué decir de la absurda visión romántica de que el arrendamiento habría anulado la enjanación entre el trabajador y la tierra? Es sorprendente que Vera no tenga en cuenta la gran corriente de trabajos teóricos y de caso sobre la utilización de formas de arrendamiento y de aparcería como relaciones de explotación de trabajo dependiente. ${ }^{93}$

No podemos esperar tampoco mucha renovación en la nueva moda historiográfica, la Nueva Economía Institucional. Su principal representante en la historia romana, Dennis Kehoe, señaló que la clase terrateniente romana poseía una "racionalidad limitada", según la cual el objetivo priorizado por la elite, antes que la maximización de las ganancias característico del agente racional neoclásico, era la seguridad de un ingreso estable (Kehoe, 1997: 16-21). ${ }^{94}$ Fue este comportamiento económico conservador lo que, según Kehoe, favoreció la adopción del arrendamiento por parte de la elite económica romana. Como ya hemos visto, es la clásica teoría de Rostovtzeff del "retiro" del propietario. El terrateniente típico no sería Columela y su forma de administración directa sino Plinio el Joven, quien supuestamente arrendaría la mayor parte de sus tierras a colonos. Pero a la hora de caracterizar el trabajo del colono en comparación con el del esclavo, no es a Rostovtzeff, sino a Rodbertus, a quien Kehoe acude. Esto queda claro en su aseveración acerca de que los cultivos care-intensive demandarían los cuidados de un colono libre interesado directamente en el aumento de la producción. ${ }^{95}$ Por otra parte el marxismo, en su variante más "politicista", no hizo más que repetir los viejos prejuicios acerca de la mentalité precapitalista del terrateniente, acercándose así, paradójicamente, a los neoinstitucionalistas. Es el caso de Ellen Meiksins Wood, que criticó la caracterización de Grecia y Roma como sociedades esclavistas, para en su lugar enfatizar su condición de "economías campesinas" determinadas por la lucha de clases entre campesinos y terratenientes (y no, por ende, entre amos y esclavos como tradicionalmente se había considerado). Meiksins Wood negaba cualquier "lógica económica" de la esclavitud, cualquier presión hacia la generación de economías de escala y de reducción de costos, características que consideraba solo propias de una economía capitalista de mercado. El arrendamiento sería la opción preferible, tanto por el gran esfuerzo que supondría una explotación esclavista centralizada y por ser también la única disponibe, debido a que el campesinado poseía derechos políticos que evitaban su explotación "extra-económica". ${ }^{96}$ Incluso los esclavos serían mayormente explotados como arrendatarios, haciendo hincapié en la importancia que habrían tenido los servi quasi coloni en el imperio romano.

Como hemos podido apreciar, históricamente se ha justificado la transición del esclavismo al colonato en base a dos argumentos de tipo subjetivo. El primero, la supuesta idea de que el colono, por estar a cargo de la explotación de su terreno,
91. Las coincidencias en el pasaje citado en la nota 5 con la postura de Staerman son realmente sorprendentes.

92. Vera incluso llega a afirmar que la explicación de Finley sobre los orígenes del colonato tardoantiguo "non sono convincenti sia per la concatenazione debole degli argomenti che per interpretazioni errate delle documentazione."

(continúa en página 157)

93. Jairus Banaji demostró ampliamente para la Antigüedad tardía la existencia de formas de "labourtenancy" en las cuales el trabajo del arrendatario-trabajador en la parcela se encuentra supervisado estrictamente por el terrateniente, siendo éste no un rentier sino más bien un entrepreneur. Incluso las formulaciones de Banaji sobre el carácter dependiente del colono bajoimperial romano son una saludable rectificación de la a todas luces anticuada teoría fiscalista del colonato (Banaji, 2001: 190-212). Para una formulación teórica de estas nuevas corrientes de interpretación, con amplia bibliografía sobre el tema (Banaji, 1997: 83-96). Véase Gill (2005: 147-171), que demuestra que la idea de la aparcería como una relación armoniosa entre clases es un mito reaccionario y fascista.

94. El concepto de "bounded rationality" fue desarrollado por Herbert Simon, un economista que sentó con sus desarrollos teóricos sobre elección racional y conducta las bases del neoinstitucionalismo moderno. Simon asume que los agentes no pueden ser plenamente racionales porque no son capaces de conocer y ordenar todas las alternativas, con lo cual son racionales hasta cierto punto. Véase al respecto Ayala Espino (1999: 11-12).

95. Si Rodbertus aunque sea consideraba que los cultivos que determinaban la necesidad del trabajo del colono eran fundamentalmente los hortícolas, en Kehoe son ya directamente los que siempre estuvieron asociados a la explotación esclavista, esto es, olivos y viñedos (continúa en página 158)

96. La similitud entre la "racionalidad limitada" de Kehoe y la “mentalidad precapitalista "de Meiksins Wood no puede estar más clara que en este pasaje: "One might conclude by asking not simply how Greek and Roman propertied classes succeeded in establishing and maintaining such a rare though 'advantageous' form of explotaition [la plantación esclavista], but why they were compelled to adopt such a complicated form, one that required. for example, not only periodic (continúa en página 158) 
97. El tan acertado símil en Morley (2000: 233-234). También Banaji ha notado "the mystifing odd reference to English landed aristocrats or Dutch rural capitalists" (Banaji, 1997: 84).

98. "Otherwise said, the DMP [el modo de producción doméstico]

harbors an antisurplus principle.

Geared to the production of livelihood, it is endowed with the tendency to come to a halt at that point. Hence if "surplus" is defined as output above the producers' requirements, the

household system is not organized

for it. Nothing within the structure of production for use pushes it to transcend itself." (Sahlins, 1972: 86).

Sahlins se inspira en los estudios de Chayanov sobre la unidad doméstica campesina, véase

Chayanov (1966: especialmente 6o-69). Véase también Astarita

(2000: 75-106, especialmente 97, donde el autor explica el contexto de estancamiento de fuerzas

productivas durante la temprana

Edad Media por la ausencia de una coacción "desde afuera" de la unidad doméstica que la impulse a trascender su lógica de consumo).

99. Así lo veía un observador de la época, citado en Beckert (2016: 326).

100. Walter Scheidel es bastante claro al respecto: "It is unlikely that the emerging "colonate" eroded the status of free worker to the extent that it undermined slave labor, and there is no sign that lots of slaves were transformed into quasi-tenants" (Scheidel, 2012: 105). También Carlos Astarita, sobre la "tesis Bloch-Duby": "El simple fundamento fáctico era más bien elusivo o faltante. Los registros sobre un juicio de ventajas comparativas por parte de los propietarios son escasos y no orientados hacia la rentabilidad, y la tesis en cuestión se erige más como postulado especulativo que como abstracción de un comportamiento social." (Astarita, 2000: 75-76).

101. "The widespread dogma that relations of production in these enterprises were structured as rent tenancies - that is, that the land was broken up into myriad smaller holdings that were simply leased out to peasants who paid some form of rent for them, usually in kind - is simply a cliché transferred to late Roman history from the popular idea of the large landowner (everywhere!) as a landlord." (Banaji, 2016: 71). tendría un mayor interés en aumentar los rendimientos que el esclavo que trabajaba en grupo. De esta forma se superaba la "alienación" entre el productor y los medios de producción y se volvía al modo de producción campesino tradicional luego del "nefasto" interludio de predominio de la esclavitud mercantil. El segundo, que el colonato respondía mejor a las inclinaciones absentistas del propietario, al permitirle desentenderse del control del proceso productivo. Los propietarios romanos pertenecerían así al mundo descripto por las novelas de Jane Austen o Anthony Throllope, donde la gentry rural inglesa vivía despreocupadamente de rentas y rara vez visitaba sus propiedades. ${ }^{97}$

Ambos razonamientos son altamente cuestionables. La antropología y los estudios sobre el campesinado han demostrado hace tiempo que las economías domésticas de subsistencia tienden a poseer una lógica de consumo "anti-excedente". ${ }^{98}$ Un hipotético ex-esclavo de cuadrilla que fuera asentado como colono trabajaría hasta cumplir con sus necesidades de consumo y con el pago de la renta; la suposición de que esta mayor libertad lo transformaría automáticamente en un acumulador es la proyección injustificada de la figura del moderno arrendatario inglés a un contexto histórico totalmente distinto. Un símil histórico más acertado es con la situación posterior a la guerra civil norteamericana, cuando las clases propietarias sureñas buscaron recrear de alguna forma la organización esclavista del trabajo que tan cuantiosos beneficios le había otorgado. Naturalmente a nadie se le ocurrió pensar que era más rentable transformar a los esclavos en aparceros o arrendatarios "libres" con amplia "autonomía productiva": sabían perfectamente que se dedicarían a cultivos de subsistencia de poco valor comercial y que bajo esas condiciones tan liberales sería muy difícil "inculcar disciplina y estímulo a los trabajadores negros". 99 Por ello la abolición de la esclavitud en los estados del sur de Estados Unidos no trajo aparejada ninguna corriente de solidaridad entre patrones y libertos: éstos últimos lucharon por realizar su trabajo como productores independientes, pero se encontraron con la oposición tenaz de sus antiguos propietarios, que buscaron por todos los medios posibles recrear los lazos de dependencia mediante "contratos obligatorios" que imponían severos controles sobre el trabajo y la movilidad (ibidem: 341-348). Incluso The Economist no se dejaba engañar, como tantos otros historiadores, acerca de las bondades económicas de la libertad: reconocía que "para la simple ejecución de grandes obras a costes reducidos no hay organización que pueda compararse a la que pone al experto europeo en lo alto del escalafón y le convierte en amo despótico del trabajador negro" y que "si la completa libertad ha de ser el principio adoptado, es claro que se hará preciso conseguir que las razas oscuras obedezcan de un modo u otro, y por propia voluntad, al hombre blanco" (citado en ibidem: 327).

Tampoco la idea del terrateniente ocioso, que prefiere dar en arriendo sus tierras, resiste el menor análisis: no existe absolutamente ninguna evidencia empírica que demuestre la supuesta instalación del esclavo como un colono, o que muestre la reorganización de la villa esclavista en un sistema de pequeñas tenencias campesinas. ${ }^{100}$ En realidad no se trata más que de un dogma bastante extendido acerca de las clases dominantes precapitalistas. ${ }^{101}$ El fundamental estudio de Kyle Harper sobre la esclavitud en la antigüedad tardía derrumbó la idea de un declive masivo de la esclavitud en el imperio a partir del siglo IV d. C. No solo es relevante el estudio de Harper por su amplia recopilación de fuentes, que demuestran la permanencia de la esclavitud como una institución clave en la sociedad romana tardía, sino también por el claro razonamiento del que se vale para demostrar la continuidad de la esclavitud. En la medida en que el empleo de esclavos estaba asociado a la producción de cultivos o manufacturas comercializables por parte de la elite, no existía ningún criterio económico para abandonar este sistema centralizado de producción. Abandonada ya la visión estancacionista tradicional del Bajo Imperio Romano, la continuación de una economía basada en los intercambios comerciales determinaba la adopción de 
economías de escala basadas en el trabajo esclavo, daslentando por ende cualquier división de la gran propiedad en pequeños arrendamientos. ${ }^{102}$ Hay que reconocer ciertamente que Pierre Dockès fue el primer autor que desembozadamente criticó la absurda teoría de la superioridad productiva del colono. Si bien en su libro de 1979 La Libération Médiévale sostenía que la villa esclavista había dado paso al pequeño arrendamiento, por lo menos no adjudicaba este fenómeno a una comparación de rentabilidades (como hacía la tesis "Bloch-Duby" según Dockès), sino a una cuestión política: la resistencia desplegada por los esclavos agrupados "en bandas" (Dockès, 1995: 45). Paradójicamente, al querer combatir las teorías "economicistas" sobre la superioridad productiva del colono sobre el esclavo, Dockès tuvo que demostrar precisamente la superioridad productiva de la villa esclavista sobre el arrendamiento para explicar que la adopción de este último sistema no respondía a un cálculo de costos (ibidem: 87). ${ }^{103} \mathrm{El}$ único inconveniente de la explotación esclavista eran los altos costos de vigilancia que generaba, el argumento "más sólido" según su opinión sobre la inconveniencia económica de la esclavitud (Dockès, 1995: 155-157). Por su parte, Carlos Astarita agregó un aspecto fundamental a la crítica de la tesis "BlochDuby" al señalar que ésta caía en la ilusión de pensar que la colocación del esclavo en la tierra en calidad de colono supuestamente liberaría al propietario de preocuparse de su mantenimiento. En realidad se trata de una falsa imagen sobre la esclavitud, que supone que todo el trabajo del esclavo le pertenece al amo, velando el hecho de que una parte del trabajo del esclavo está dirigido a la reproducción del esclavo-trabajador. ${ }^{104}$ Es de lamentar que Chris Wickham, quien por un lado criticó acertadamente la supuesta incompatibilidad entre el latifundio y la explotación esclavista, ${ }^{105}$ por el otro sea también víctima de esta "ilusión" generada por la forma esclavista del trabajo, al creer que la relación de arrendamiento le permitía una mayor flexibilidad al propietario, ya que no debía costear su mantenimiento, como supuestamente solo sucedería en el caso de la relación esclavista. ${ }^{106}$

Después de este largo recorrido, una conclusión cae de maduro: ya no es razonable hablar de una transición de la esclavitud al colonato, y mucho menos hacerlo en base a supuestas relaciones sociales naturales o mediante razonamientos subjetivos incomprobables. Tanto desde un punto de vista cultural ${ }^{107}$ como económico, ${ }^{108}$ la esclavitud fue una variable esencial de la sociedad romana, cuya influencia tiñó todas las demás relaciones sociales, desde el trabajo asalariado ocasional hasta el arrendamiento de tierras. ${ }^{109}$ Esta noción precisamente permite apreciar que no hubo un desplazamiento de otras relaciones sociales, sino un proceso de complementariedad. Hace tiempo se ha demostrado que la rentabilidad de la explotación esclavista dependía vitalmente de la utilización de mano de obra libre, principalmente proveniente del campesinado local (Rathbone, 1981: 10-23). También se ha esbozado la posibilidad de una complementariedad al interior de la villa entre un sector "capitalista", basado en el trabajo esclavo, y otro sector de "economía campesina", compuesto por pequeños arrendatarios, similar al modelo esbozado por Witold Kula para la economía feudal polaca del siglo XVII (Corbier, 1981: 427-444; Kula, 1974). La recuperación de estas formas de complementariedad, en la línea que ya habían marcado Fustel de Coulanges y Max Weber, puede conjugarse con los recientes desarrollos teóricos sobre la teoría marxista de los modos de producción (Banaji, 2010), que propone no caracterizar enteras épocas históricas por una supuesta forma de explotación particular (como se ha hecho a menudo en todo el debate sobre la transición del esclavismo al colonato), sino subrayar que los procesos productivos, en nuestro caso principalmante la agricultura, suponen formas complejas y diferenciadas de explotación del trabajo. ${ }^{110}$ De esta forma se abrirá una alternativa que permita dejar atrás nociones ingenuas o idealizadas de las relaciones sociales, cuyas justificaciones residen en última instancia en la repetición acrítica de viejos y agotados prejuicios.
102. "If, for instance, specialized workers such as vintners could be profitably employed on farms exceeding the normal size or tenant plots, then there were advantages to organizing production in larger units. Indeed, there is conderable evidence for specialized workers on Roman estates, suggesting that one reward for control rather than devolution was the opportunity to utilize the particular skills of specialized laborers on larger farms." (Harper, 2011: 159).

103. Dockès resaltaba no obstante con cierta reticencia las mejoras de productividad que ocasionaba el trabajo esclavo: "El recurso al equipo servil en los latifundia permite algunas economías extraídas de la división del trabajo y más generalmente de la cooperación.

(continúa en página 158)

104. "In other words, the owner does not have outlays' related to the slave's upkeep;

(continúa en página 158)

105. Criticando la teoría de Andrea Carandini, prácticamente igual a la de Staerman sobre la transición del esclavismo al colonato, Wickham fue bastante menos diplomático que Finley: (continúa en página 159)

106. En esto se basa la propuesta alternativa de Wickham a la tesis "Staerman-Carandini", ciertamente similar a la que en su momento formulara Otto Neurath: "It may be that a further line of approach could be pursued-one that is occasionally touched on but not developed by Carandini and his associates: the relative flexibility of slave $v$. tenant production. Tenant production contains within it an independent subsistence sector: the tenant family (slave or free) provides for itself" (ibidem: 189).

107. "From a cultural point of view, therefore, slavery was at no time an incidental feature of Roman social organisation and at no time an inconsequential element of Roman mentality." (Bradley, 1994: 29).

108. Para la temprana presencia de explotaciones rurales con esclavos antes del boom de la economia drogata, véase Scheidel (2012: 103), donde se señala que las granjas helenísticas de producción para el mercado fueron un antecedente de la villa romana. Según algunos indicios de la arqueología, se podría rastrear la existencia de esclavos rurales ya en el siglo IV a. C., véase Rathbone (1983: 162). 109. Para la esclavitud como "forma arquetípica del trabajo no libre", véase De Ste. Croix (1981: 173). 110. Para una tentativa en este sentido, véase Rosafio (1994: 145-158). 


\section{Notas}

7 "Nel corso della trasformazione, l'organizzazione della manodopera su cui si fondava l'agricoltura schiavistica divenne obsoleta, le ville in particolare; una parte, il cui mantenimento era diventato antieconomico, fu abbandonata, (...) Riducendo il processo a formula, si può dire che quanto più si concentrò la propietà, tanto più si frazionò la produzione. E così, nel mentre a livello di amministrazione patrimoniale si unificavano plurimi fondi in grandi aggregati, le massae fundorum, la forza lavoro veniva parcellizzata in una miriade di contadini affituari gestori di aziende contadine di taglia familiare.” (ibidem: 497). (En página 138.)

12 Nos basamos aquí en las advertencias que Pierre Bourdieu, Jean-Claude Chamboredon y Jean-Claude Passeron realizaron acerca de la influencia de los prejuicios y del sentido común en la conformación del objeto de investigación, y de la necesidad de analizar críticamente este tipo de formulaciones: "On ne peut faire l'économie de la tâche de construction de l'objet sans abandonner la recherche à ces objets préconstruits, fait sociaux découpés, perçues et nommés par la sociologie spontanée ou "problèmes sociaux» dont la prétention à exister comme problèmes sociologiques est d'autant plus grande qu'ils ont plus de réalité sociale pour la communauté des sociologues." (Bourdieu, Chamboredon, y Passeron, 2005: 52-53). (En página 138.)

15 Estas nociones se aplicaron también a la civitas romana primitiva, como lo hizo José Luis Romero en La cultura occidental, en donde contraponía el ideal romano de vida, de virtud republicana como realización de servicio a la comunidad, a la noción cristiana de desprecio de la vida pública y terrenal: “Como miembro de una comunidad política, el romano aspiraba a realizarse como ciudadano, distinguiéndose en las funciones públicas, recorriendo el cursus honorum y alcanzando una gloria terrena cuya expresión era la perennidad del recuerdo. Riqueza y poder acompañaban subrepticiamente a esta idea de la gloria obtenida por el servicio de la comunidad, como aspiraciones del romano, para quien la vida se realizaba sobre el mundo terreno y para quien la muerte constituía ese vago reino de sombras que Virgilio había descripto en el canto VI de la Eneida. A esa concepción de la vida estaba indisolublemente unido el destino de Roma." (Romero, 2004: 28-29). (En página 139.)

17 A continuación Taylor hace un sugerente comentario sobre la actualidad de la teoría romántica de la expresión: "The complaint against the Enlightenment, and the society which had developed in modern times, is now directed against technological society which is in so many ways the heir of the Enlightenment. In our day, too, it is reproached for dividing reason from emotion, thought from feeling, for narrowing men and blunting their creativity, and in the process deforming them and thus dividing them from each other in a class society, and hence negating the community with which men can identify and confronting them instead with naked power which denies them freedom." (ibidem: 28-29). Como veremos a continuación, la historiografía de la antigüedad no fue una excepción al respecto. Sirva como otro ejemplo todo el reciente debate sobre la no "estatalidad" de la polis, que ha reflotado precisamente toda esta visión romántica de Grecia, véase Berent (1996: 36-59). (En página 139.)

19 “Im griechischen Prinzip haben wir die Geistigkeit in ihrer Freude, in ihrer Heiterkeit und in ihrem Genüsse gesehen: der Geist hatte sich noch nicht in die Abstraktion zurückgezogen, er war noch mit dem Naturelemente, mit der Partikularität der Individuen behaftet, weswegen die Tugenden der Individuen selbst sittliche Kunstwerke wurden. (...) Hier in Rom finden wir nunmehr die freie Allgemeinheit, diese abstrakte Freiheit, welche einerseits den abstrakten Staat, die Politik und die Gewalt über die konkrete Individualität setzt und diese durchaus unterordnet, andererseits dieser Allgemeinheit gegenüber die Persönlichkeit erschafft - die Freiheit des Ichs in sich, welche wohl von der Individualität unterschieden werden muß. Denn die Persönlichkeit macht die Grundbestimmung des Rechts aus: sie tritt hauptsächlich im Eigentum ins Dasein, ist aber gleichgültig gegen die konkreten Bestimmungen des lebendigen Geistes, mit denen es die Individualität zu tun hat." (Hegel, 1970: 339-340). (En página 139.) 
21 Hegel colocaba el gran desarrollo de la esclavitud ya en la época del conflicto entre patricios y plebeyos, pero esta descripción vale también para el período posterior, como se desprende de su propio relato: "Alle obrigkeitliche und richterliche Gewalt und alles Grundeigentum des Staats befand sich um diese Zeit in den Händen der Patrizier, das Volk aber, unaufhörlich in den Krieg hinausgerissen, konnte sich nicht mit friedlichen Beschäftigungen abgeben, die Gewerbe konnten nicht blühen, und der einzige Erwerb der Plebejer war der Anteil, den sie an der Beute hatten. Die Patrizier ließen ihren Grund und Boden durch Sklaven bebauen und gaben von ihrem Ackerland an ihre Klienten, welche gegen Abgaben und Beisteuern, also als Pächter, den Nießbrauch derselben hatten. Dieses Verhältnis war durch die Art der Beisteuer der Klienten dem Lehnsverhältnis sehr ähnlich: sie mußten Beisteuer geben zur Verheiratung der Töchter des Patronus, um den gefangenen Patron oder dessen Söhne loszukaufen, um ihnen zu obrigkeitlichen Ämtern zu verhelfen oder das in Prozessen Verlorene zu ersetzen.”, ídem, p. 364. "Der Reichtum wurde als Beute empfangen und war nicht Frucht der Industrie und rechtschaffener Tätigkeit...” (ibidem: 374-375). (En página 139.)

25 "To the slave cultivators of ancient times, gradually succeeded a species of farmers known at present in France by the name of Metayers. They are called in Latin, Coloni Partiarii. (...) Land occupied by such tenants is properly cultivated at the expence of the proprietor, as much as that occupied by slaves. There is, however, one very essential difference between them. Such tenants, being freemen, are capable of acquiring property, and having a certain proportion of the produce of the land, they have a plain interest that the whole produce should be as great as possible, in order that their own proportion may be so." (ibidem:389). Sobre el origen y desarrollo de la ideología de la libertad económica y sus supuestos beneficios, véase Temperley (1977: 94-118, especialmente 106-109). (En página 140.)

30 "La population rurale dans tout l'empire romain étoit divisée en déux classes: les colons libres et les esclaves, qui différoient bien plus de nom que par des droits réels. Les premiers cultivoient la terre moyennant des redevances fixes, payables le plus souvent en nature; mais comme une distance prodigieuse les séparoit de leurs maîtres, qu'ils relevoient immédiatement de quelque esclave favori ou de quelque affranchi, que leurs plaintes nétoient point écoutées, et que les lois ne leur donnoient aucune garantie, leur condition étoit devenue toujours plus dure..." (Sismondi, 1835: 32-33). A su vez la recuperación del tradicional método de aparcería en época ostrogoda traería nuevamente la prosperidad perdida: "Peut-être aussi, et les expressions de l'historien Procope peuvent à cet égard faire maître un doute, imposa-t-il au cultivateur romain l'obligation de livrer à son maître barbare seulement le tiers de sa récolte; alors il auroit le mérite d'avoir introduit de nouveau en Italie le système des colons partiaires ou métayers, auxquels cette contrée doit la prospérité de sa population agricole." (ibidem: 290). (En página 141.)

31 Mill llegaba incluso a citar al poeta romántico Wordsworth como prueba de las bondades de la sociedad campesina: "No other agricultural population in England could have furnished the originals of Wordsworth's peasantry” (Mill, 1895: 179). La extensión del mito es abrumadora: “Además de un género literario propio, el idilio pastoril, la idealización del campo y del campesino tiene una tradición tan larga y variada que se corre el riesgo de caer en la enumeración caótica: la historia de Tácito, las odas de Horacio, las amonestaciones de Catón el Viejo, Rousseau, los románticos ingleses y alemanes, Ruskin, Morris, los prerrafaelistas, Thoreau, Edward Carpenter, Tolstoi, Hudson, Hamsut, Munthe, Tagore, Kipling, Barres, David Lawrence, Spengler, Ford, Jünger, Heidegger, Martínez Estrada, Pilniak, Carlo Levi, los sureños norteamericanos, los nazis y hasta los ecologistas radicales y los urbanistas posmodernos" (Sebreli, 1991: 121). (En página 141.)

39 "Der Patronus wie der Colonus wussten ja beiderseits genau, wie viel das Gut in bessern und in schlechtern Jahren eintrug, und was der Colonus bedurfte und was ihm zukam, stand durch hundertjährige Gewohnheit fest. Weder dieser mit den Seinigen sollte dabei Not leiden, noch jener an seinem rechtmässigen Einkommen einbüssen. Jeder tat sein Bestes, der Patron durch Beaufsichtigung, einsichtsvollen Rat, Schutz und im erforderlichen Falle durch baare Unterstützung und Bewilligung von Hülfsknechten: der Colone durch flei igsten Betrieb der Wirtschaft und redliche Ablieferung der Ueberschüsse. Eine ratio fiduciaria, eine Vertrauensrechnung war es also durch die der Colone beim Lustralschlusse seine Treue gegen den Patron dartat.", ídem. Se trata de la misma caracterización que Thedor Mommsen desarrolló en su Römische Geschichte, en donde la primitiva nobleza rural, asentada en la tierra y ocupada en las tareas agrícolas (no corrompida todavía por el flujo de riqueza monetaria), establecía una relación justa y 
cordial entre esta clase superior y la masa de los labradores. Todo cambiaría con el advenimiento de la Grosswirtschaft, de la explotación de trabajo esclavo a gran escala y de la "verderbliche Institution der Mittelmänner" (Mommsen, 1856: 177). (En página 142.)

42 "Bei Latifundien ist dagegen stets eine Menge dienender Hände nötig, und überall wo sich deren in grosser Anzahl finden, gehört es zu den Hauptfragen über den Zustand des gemeinen Volkes, in welcher Weise dem angedeuteten hier vorhandenen Bedürfniss genügt werde. Hier wurden nun von jehr im Römischen Staate eine Menge von Sclaven zu den Geschäftes der Ackerhaus und der Viehzucht verwendet. Viele Grundstücke der Reichen waren ausserdem in Zeitpacht gegeben, oder nach emphyteutuschen Rechte ausgethan. Ganz besonders aber kommt hier in Betracht die Bebauung durch Colonen, an welche einzelne Bauerhöfe aufden grösseren Besitzungen gegen einen jährlichen, der Regel nach in Frucht zu entrichtenden canon ausgegeben wurden." (Gaupp, 1844: 75-76). (En página 142.)

48 Aquí precisamente se encuentra in nuce la famosa distinción popularizada mucho después por Staerman entre propiedad territorial y extraterritorial, que correspondería cada cual a una forma de explotación distinta, la una intensiva y con esclavos, la otra extensiva y con colonos: “car, d'un côté, les propietés territoriales à l'entour de Rome étaient trop recherchées et d'une trop grande valeur pour être abandonëes au colonat; d'un autre côté, le colonat ne put être appliqué que dans les latifundia, qui étaient particulierement convoités par les grandes families, de préférence aux propiétés de moindre étendue pour lesquelles avaient spécialement écrit les auteurs dont je viens de parler;" (ibidem: 162). (En página 143.)

56 Este retorno a una economía natural se apreciaba en la renta en producto con la que el esclavo instalado tributaba al propietario: “Der erste ist der Uebergang aus der Latifundienwirtschaft in die Parcellen- und Zwergwirtschaft, der sich in der Zeit zwischen dem älteren und jüngeren Plinius so machte, da die Grundbesitzer Parcellen ihrer bisherigen Grossgüter an eigene Sklaven gegen Naturalpacht überliessen; er führt hauptsächlich zum Colonat” (Rodbertus, 1864: 207). La ligazón entre colonato (y por extensión arrendamiento) con una idea primitivista de la economía antigua, muy extendida hasta la actualidad, había tenido en Rodbertus a su primer exponente. Max Weber reconocía a Rodbertus la originalidad del enfoque primitivista: "Für den Groshaushalt der Antike hat Rodbertus zuerst den Ausdruck "Oikos" verwendet, dessen Begriffsmerkmal die - prinzipielle - Autarkie der Bedarfsdeckung durch Hausangehörige oder haushörige Arbeitskräfte, welchen die sachlichen Beschauffungsmittel tauschlos zur Verfügung stehen, sein sollte." (Weber, 1922: 69). (En página 144.)

60 Hallamos la misma idea en Marx y Engels, influenciados sin duda por el estudio de Rodbertus: “Die aufSklavenarbeit gegründete Latifundienwirtschaft rentierte sich nicht mehr; sie war aber damals die einzig mögliche Form der großen Agrikultur. Die Kleinkultur war wieder die allein lohnende Form geworden. Eine Villa nach der andern wurde in kleine Parzellen zerschlagen und ausgegeben an Erbpächter, die eine bestimmte Summe zahlten, oder partiarii, mehr Verwalter als Pächter, die den sechsten oder gar nur neunten Teil des Jahresprodukts für ihre Arbeit erhielten. Vorherrschend aber wurden diese kleinen Ackerparzellen an Kolonen ausgetan, die dafür einen bestimmten jährlichen Betrag zahlten, an die Scholle gefesselt waren und mit ihrer Parzelle verkauft werden konnten; sie waren zwar keine Sklaven, aber auch nicht frei, konnten sich nicht mit Freien verheiraten, und ihre Ehen untereinander wurden nicht als vollgültige Ehen, sondern wie die der Sklaven als bloße Beischläferei (contubernium) angesehn. Sie waren die Vorläufer der mittelalterlichen Leibeignen." (Engels, 1962: 144). Este fragmento de Engels fue tomado como el hilo conductor de toda la posterior investigación soviética, y marxista en general. (En página 145.)

63 En este aspecto Heisterbergk coincidía con Rodbertus en que una explotación intensiva de la tierra requería necesariamente de la pequeña producción, con lo cual la gran explotación esclavista quedaba descartada como una opción disponible para los propietarios en las provincias: “Wenn die Steuerplifchtigkeit des Bodens den Grossgrundherrn das freie Schalten mit ihrem Grund und Boden, die freie Wahl zwischen Bewirtschaftung und Nichtbewirtschaftung untersagte, so durften sie sich doch wenigstens jeder eigenen Sorge um die Bewirtschaftung entschlagen, sobal die, anstatt eine der eingehendsten Leitung bedürfende Sclavenwirtschaft einzuführen, die bisherige Wirtschaftform beibehielten, $d$. h. die bisherigen, durch die Latifundienbildung enteigneten Kleinbesitzer als Kleinwirte auf ihren ehemaligen Grundstücken beliessen und sich mit der Pachtpflichtigkeit derselben begnügten.” (ibidem: 79). (En página 145.) 
67 En su trabajo L'alleu et le domaine rural, que forma parte de su monumental Histoire des institutions politiques de l'ancienne France, Fustel rastreaba los orígenes del dominio señorial en la villa romana. Allí encontraba en germen la división entre reserva señorial y manso de los señoríos rurales medievales, que corresponderían, respectivamente, al fundo explotado de forma directa mediante esclavos por el propietario y a las tenencias dadas en arriendo a colonos, véase Fustel De Coulanges (1889: 61-87). Por su parte Weber señalaba que con el advenimiento de la edad imperial, se daba una transformación del lugar del colono en la organización productiva. Debido a la caída numérica de la fuerza de trabajo esclava por el final de la expansión territorial, los propietarios debieron recurrir entonces al trabajo de los colonos, principalmente en momentos cruciales del ciclo agrícola, como la cosecha. Estos colonos estarían en un lugar intermedio entre un pequeño propietario independiente y un jornalero, aunque en un pasaje sorprendente, Weber señalaba que esta forma de arrendamiento ocultaba en realidad una relación laboral: "Wir sprechen hier diejenige Bildung, welche die relativ grösste politische und wirtschaftliche Uebermacht des Grundherrn enthält und wo also das Pachtverhältnis ein verschleieters Arbeitsverhältnis ist." (Weber, op. cit.: 249). Vemos que la postura de Weber se acercaba mucho a la noción de complementariedad entre trabajo esclavo y trabajo libre que marcaba Fustel. Otros autores que indagaron en el mismo sentido: Pernice (1898: 82-183, especialmente 90-91), Kübler (1900: 561-588, especialmente 580). La primera monografía marxista del tema, la tesis doctoral de Hendrik Bolkestein De colonatu romano eiusque origine, de 1906, coincidía con Weber en el rol fundamental de los servicios laborales del colono: "Nova culturae ratio introducebatur: ager circa villam ab ipso domino (vel hujus vicario) ope mercenariorum vel servorum exercebatur, reliqui agri, in particulas divisi, colonis locabantur; haec culturae ratio in latifundiis aetate imperatoria solita fuit, uti apparet ex Digestis. Colonis opponitur conductor (grootpachter), qui cum familia servorum ipsius villae curae praeest." (Bolkestein, 1906: 141). Hermann Gummerus, discípulo de Edward Meyer y crítico de la la Oikenwirtschaftstheorie de Rodbertus y Bücher, apoyada en cierta medida por Weber, criticó a este último por considerar que los coloni de Columela debían proveer de corveas al terrateniente, aunque no descartó tampoco que pudieran ser contratados como mano de obra asalariada en la villa principal: "Obwohl die Kolonen nicht kontraktmässig zu Frohnden verpflichtet waren, so haben sie doch wahrscheinlich mehr oder weniger freiwillig als Lohnarbeiter auf dem Herrenlande gearbeitet." (Gummerus, 1906: 96). (En página 146.)

74 Lot caracterizaba al capitalismo como un "régimen en el cual todas las fuerzas de la sociedad tienden a la producción de valores que se vierten en mercados cada vez más extendidos" (idem: 52). Si bien Lot hacía uso de la distinción entre "economía monetaria" y "economía natural”, aplicando la primera al esplendor del imperio romano, éste nunca habría llegado a configurar un sistema capitalista debido a la ausencia de inversión productiva del capital, tanto por la falta de condiciones técnicas (altos costos del transporte, poca integración de los mercados), como por la mentalidad usurera y rentística de la aristocracia romana. Parafraseando a Salvioli, Lot señalaba que "El capitalismo romano no era otra cosa que una débil capa barrida por el soplo de la tempestad, y la roca subyacente de la economía natural reapareció muy pronto." (ibidem: 73). (En página 147.)

82 Ídem. Esta idea tendrá mucha influencia en la historiografía medieval. Georges Duby repetía prácticamente el mismo argumento de Bloch para explicar la generalización de relaciones serviles durante la temprana Edad Media: “L'apparition et la multiplication des tenures paysannes au viie siècle sont donc également la conséquence d'une innovation de très grande portée: une manière nouvelle d'utiliser la main-d'oeuvre servile. Il semble que les grands propriétaires aient découvert à cette époque qu'il était profitable de marier certains de leurs esclaves, de les caser dans un manse, de les charger d'en cultiver les terres attenantes et de nourrir ainsi leur famille. Le procédé déchargeait le maître, réduisant les frais d'entretien de la domesticité; il stimulait l'ardeur au travail de l'équipe servile et en accroissait la productivité; il assurait aussi son renouvellement, puisqu'il confiait aux couples d'esclaves le soin d'élever eux-mêmes leurs enfants jusqu'à ce qu'ils fussent en âge de travailler. Ce dernier avantage devint sans doute, peu à peu, le plus évident." (Duby, 1973: 50-51). (En página 149.)

92 Vera incluso llega a afirmar que la explicación de Finley sobre los orígenes del colonato tardoantiguo "non sono convincenti sia per la concatenazione debole degli argomenti che per interpretazioni errate delle documentazione." (Vera, 2007: 493). Cabe preguntarse si por “argumentación fuerte” se entiende la repetición de viejos prejuicios ideológicos de más de doscientos años de antigüedad, y si por 
“interpretación correcta de la documentación”, la total ausencia de base documental, como bien lo expuso Jairus Banaji sobre las teorías de Vera: "The direct management of the early middle ages was certainly a Roman legacy. The contrary view, viz. that Roman landowners gave up direct management when they abandoned the slave-mode, of Wickham himself and, for example, Pasquali, stems chiefly from Domenico Vera, but it is crucial to note that Vera's reconstructions lack any documentary base even vaguely comparable to papyrological archives, Merovingian charters or Carolingian inventories. (Reconstructing estate-management from a collection of letters, even those of an aristocrat, is a bit like trying to grasp the structure of the labour-process in a large manufacturing firm from the correspondence of its shareholders)" (Banaji, 2010: 203-204). La última afirmación de Banaji se aplica enteramente a toda la historiografía que quiso justificar un cambio en el modo de producción del imperio romano en el siglo Il d. C. en base a un par de cartas de Plinio el Joven donde se menciona la presencia de colonos. (En página 151.)

95 Si Rodbertus aunque sea consideraba que los cultivos que determinaban la necesidad del trabajo del colono eran fundamentalmente los hortícolas, en Kehoe son ya directamente los que siempre estuvieron asociados a la explotación esclavista, esto es, olivos y viñedos: “Olive trees and vines are "care-intensive" crops, which require a great deal of attention over a long period of time before they can produce a crop. Such crops are to be contrasted with "effort-intensive" crops, which require a great deal of labor, but not necessarily skilled labor. Wheat could be viewed as such a crop. When care-intensive crops are cultivated with slave labor, there is a need for substantial supervision to make sure that the slaves perform the appropriate tasks in a timely manner. In many circumstances, landowners could reduce their own costs of monitoring by assigning the task of cultivating olive trees to tenants. The tenants would then have a much greater incentive than slaves or even wage laborers to engage in sufficiently careful cultivation, since they would be able to profit from their investment of labor and resources." (Kehoe, 2005: 65). (En página 151.)

96 La similitud entre la "racionalidad limitada" de Kehoe y la "mentalidad precapitalista "de Meiksins Wood no puede estar más clara que en este pasaje: "One might conclude by asking not simply how Greek and Roman propertied classes succeeded in establishing and maintaining such a rare though 'advantageous' form of explotaition [la plantación esclavista], but why they were compelled to adopt such a complicated form, one that required, for example, not only periodic coercive acts of appropriation but a continuosly coercive supervision of production, as well as an elaborate and expensive state apparatus to support it. It is not surprising that an ancient agricultural authority like Columella in his De Re Rustica (I.vii.4-7) should question the practicability of allowing slaves to work agricultural land when the landlord is unable to supervise them directly (as must have been frequently the case in ancient Greece and Rome where large proprietors often owned several widely scattered holdings); in such cases, he suggests, tenants are preferable." (Meiksins Wood, 2002: 46). (En página 151.)

103 Dockès resaltaba no obstante con cierta reticencia las mejoras de productividad que ocasionaba el trabajo esclavo: “El recurso al equipo servil en los latifundia permite algunas economías extraídas de la división del trabajo y más generalmente de la cooperación. No quiero en modo alguno exagerar su importancia, al contrario." (ibidem: 149). A pesar de su tímida afirmación, hay que reconocer en Dockès este rasgo de lucidez. Otros autores no han tenido la misma sagacidad: criticando precisamente a Dockès, Meiksins Wood nunca pudo entender "why it became necessary for landlords to adopt a form of exploitation that required concentration of property to make it economically feasible." (Meiksins Wood, 2002: 27). (En página 153.)

104 "In other words, the owner does not have outlays' related to the slave's upkeep; but still a part of what the slave produces is assigned to the personal consumption of the same slave, even though it appears as if the owner is giving the slave an allowance of supplies for his subsistence." (Astarita, 2015: 124). Astarita rescata las reflexiones de Marx sobre las formas aparenciales del trabajo esclavo y del trabajo asalariado: "Bei der Sklavenarbeit erscheint selbst der Theil des Arbeitstags, worin der Sklave nur den Werth seiner eignen Lebensmittel ersetzt, den er in der That also für sich selbst arbeitet, als Arbeit für seinen Meister. Alle seine Arbeit erscheint als unbezahlte Arbeit. Bei der Lohnarbeit erscheint umgekehrt selbst die Mehrarbeit oder unbezahlte Arbeit als bezahlt. Dort verbirgt das Eigenthumsverhältniß das Fürsichselbstarbeiten des Sklaven, hier das Geldverhältniß das Umsonstarbeiten des Lohnarbeiters." (Marx, 1987: 502). (En página 153.) 
105 Criticando la teoría de Andrea Carandini, prácticamente igual a la de Staerman sobre la transición del esclavismo al colonato, Wickham fue bastante menos diplomático que Finley: "Carandini's explanation for the crisis of the slave mode, the expansion of optimal medium-sized estates to a level at which the supervision needed for them became uneconomic, leading to an involution of the system, has also been heavily criticized, mostly on the grounds that such an expansion is ill-documented (Pliny when he bought new estates did not unify their organization with his old ones), and anyway inexplicable -why should people be so stupid as to render their estates uneconomic?” (Wickham, 1988: 188). (En página 153.) 


\section{Q Bibliografía}

"Astarita, C. (2000). “La primera de las mutaciones feudales”, Anales de Historia Antigua, Medieval y Moderna, 33, pp. 75-106.

"Astarita, C. (2015). "Origins of the medieval craftsmen", en Da Graca, L. y Zingarelli, A., Studies in precapitalist modes of production, Brill.

» Ayala Espino, J. (1999). Instituciones y economía. Una introducción al neoinstitucionalismo económico, México, FCE.

» Banaji, J. (1992). “Historical Arguments for a 'Logic of Deployment' in 'Pre-Capitalist' Agriculture”, Journal of Historical Sociology, 5, pp. 379-391.

» Banaji, J. (2010). Theory as History. Essays on Modes of Production and Explotaition, Brill, Londres.

» Banaji, J. (1997). "Modernizing the Historiography of Rural Labour: An Unnwritten Agenda", en Bentley, M. (ed.), Companion to Historiography, Routledge, pp. 83-96.

» Banaji, J., y TEDESCO, P. (2017). “Giuseppe Salvioli's Capitalism in the Ancient World”, The Journal of European Economic History, 3, pp. 145-156.

»Banaji, J. (2016). Exploring the Economy of Late Antiquity, Cambridge, Cambridge University Press.

» Beckert, S. (2016). El imperio del algodón. Una historia global, Barcelona, Crítica.

"Berent, M. (1996). “Hobbes and the 'greek tongues”, History of Political Thought, 17, 1, pp. 36-59.

» Berlin, I. (1999). The Roots of Romanticism, Princeton, Princeton University Press.

»Bloch, M. (1947). “Comment et pourquoi finit l'esclavage antique”, Annales. Histoire, Sciences Sociales, Año 2, 1, pp. 30-44.

» Bolkestein, H. (1906). De colonatu romano eiusque origine, Amsterdam.

» Bourdieu, P., Chamboredon, J. C., y Passeron, J. C. (2005). Le métier de sociologue. Préalables épistémologiques, Berlín y Nueva York, Mouton de Gruyter.

»Bradley, K. (1994). Slavery and Society at Rome, Cambridge, Cambridge University Press.

" Clausing, R. (1925). The Roman Colonate. The Theories of its Origin, Nueva York, Columbia University Press.

»Corbier, M. (1981). "Propietà e gestione della terra: grande propietà fondiaria e economia contadina" en Giardina, A., y Schiavone, A., Società romana e produzione schivistica. L'Italia: Insediamenti e forme economiche, Roma, pp. 427-444.

" Chayanov, A. V. (1966). The Theory of the Peasant Economy, The American Economic Association, Homewood.

"De Ste. Croix, G. E. M. (1981). The Class Struggle in the Ancient Greek World, Londres.

» Dockès, P. (1995). La liberación medieval, México, Fondo de Cultura Económica.

»Duby, G. (1973). Guerriers et Paysans, VII-XIle siècle. Premier essor de l'économie européenne, París, Gallimard.

»Engels, F. (1962). “Der Ursprung der Familie, des Privateigentums und des Staats”, Marx Engels Werke, Berlín. 
» Fernández Ubiña, J. (1982). La crisis del siglo IIl y el fin del mundo antiguo, Madrid, Akal.

» Finley, M. (1982). Esclavitud antigua e ideología moderna, Barcelona, Crítica.

» Frank, T. (2004). An economic History of Rome, Kitchener, Batoche Books.

» Fustel De Coulanges, N. D. (1885). Recherches sur quelques problèmes d'histoire, Paris.

» Fustel De Coulanges, N. D. (1889). Histoire des institutions politiques de l'ancienne France, París.

» Gaupp, E. T. (1844). Die germanische Ansiedlungen und Landtheilungen in den Provinzen des roemischen Westreiches, Breslau.

» Gill, D. (2005). “Tuscan Sharecropping in United Italy: The Myth of Class Collaboration Destroyed” en Byres, T. (ed.), Sharecropping and Sharecroppers, Londres, Frank Cass, pp. 147-171.

» Giraud, Ch. (1844). Essai sur L' Histoire du droit français au moyen âge, Paris.

» Gummerus, H. (1906). Der römische Gutsbetrieb als wirtschaftlicher Organismus nach den Werken des Cato, Varro und Columella, Leipzig.

"Harper, K. (2011). Slavery in the Late Roman World, AD 275-425, Cambridge, Cambridge University Press.

» Hegel, G. W. F. (1970). Vorlesungen über die Philosophie der Geschichte. Werke 12., Frankfurt am Main, Suhrkamp.

» Hegel, K. (1847). Geschichte der Städteverfassung von Italien, Leipzig.

» Heisterbergk, H. (1876). Die Entstehung des Colonats, Leipzig.

» Heitland, W. E. (1921). Agricola. A Study of Agriculture and Rustic Life in the Greco-Roman World from the Point of view of Labour, Cambridge, Cambridge University Press.

» Kaufmann, W. (1978). Hegel. A Reinterpretation, Notre Dame, University of Notre Dame Press.

" Kehoe, D. (1997). Investment, Profit and Tenancy. The Jurists and the Roman Agrarian Economy, Ann Arbor, The University of Michigan Press.

»Kehoe, D. (2005). Law and the Rural Economy in the Roman Empire, Ann Arbor, The University of Michigan Press.

» Kübler, B. (1900). "Sklaven und Colonen in der römischen Kaizerseit”, Festschrift Johannes Vahlen, Berlín, pp. 561-588.

» Lot, F. (1956). El fin del mundo antiguo y los comienzos de la Edad Media, México.

» Marx, K. (1987). Gesamtausgabe: (MEGA), Abt. 2. “Das Kapital” und Vorarbeiten Bd. 6. Das Kapital, Kritik der politischen Ökonomie: 1.Bd, Berlin.

» Mazzarino, S. (1961). El fin del mundo antiguo, México, UTEHA.

» Meiksins WOOD, E. (2002). “Landlords and Peasants, Masters and Slaves: Class relations in Greek and Roman Antiquity”, Historical Materialism, Vol. 10, № 3, pp. 17-69.

» Mill, J. S. (1895). Principles of Political Economy with Some of their Applications to Social Philosophy, Londres, George Routledge and Sons.

» Mommsen, Th. (1856). Römische Geschichte, Berlín.

» Mommsen, Th. (1880). “Decret des Commodus für den Saltus Burunitanus”, Hermes, 15 , pp. 385-411.

» Morley, N. (2000). “Review of Kehoe, D., Investment Proft and Tenancy”, JRS, Vol. 90, pp. 
233-234.

» Neurath, O. (2005). Economic Writings. Selections 1904-1945, Nueva York, Kluwer.

» Pernice, A. (1898). “IV. Parerga”, Zeitschrift der Savigny-Stiftung für Rechtsgechichte, 19, pp. 82-183.

»Puchta, G. F. (1842). Cursus der Institutionem, Leipzig.

" Rathbone, D. (1983). “The slave mode of production”, The Journal of Roman Studies, 73.

» Rathbone, D. (1981). "The Development of Agriculture in the "Ager Cosanus" during the Roman Republic: Problems of Evidence and Interpretation", The Journal of Roman Studies, Vol. 71, pp. 10-23.

» Revillout, Ch. (1856). “Étude sur l'histoire du colonat”, Revue historique de droit francais et étranger, 2, pp. 417-46o.

» Rodbertus, K. J. (1864). “Zur Geschichte der agrarischen Entwickelung Roms unter den Kaisern oder die Adscriptitier, Inquilinen und Colonen”, Jahrbuch für Nationalökonomie und Statistik, 2, pp. 206-268.

» Romero, J. L. (2004). La cultura occidental, Siglo XXI, Buenos Aires.

» Rosafio, P. (1994). “Slaves and coloni in the villa system”, en Carlsen, J. et alii (eds.), Landuse in the Roman Empire, Roma, pp. 145-158.

» Rostovtzeff, M. (1958). The Social and Economic History of the Roman Empire, Oxford.

»Sahlins, M. (1972). Stone Age Economics, Nueva York y Chicago, Aldine-Atherton.

»Salvioli, G. (1906). Le Capitalisme dans le monde antique, Paris.

» Savigny, F. K. (1823). Über den Römischen Colonat und über die Römische Steuerverfassung unter den Kaisern, Berlín.

» Scheidel, W. (2012). "Slavery” en Ídem (ed.), The Cambridge Companion to the Roman Economy, Cambridge, pp. 89-113.

» Schiller, F. (1875). Briefe über die ästhetische Erziehung des Menschen, Leipzig.

» Schultz, C. L. F. (1833). Grundlegung zu einer geschichtlichen Staatswissenschaft der Römer, Colonia.

» Sebreli, J. J. (1991). El asedio a la modernidad, Buenos Aires, Sudamericana.

» Serrigny, D. (1862). Droit public et administratif romain, II, París.

"Sismondi, J. C. L. Simonde de, Histoire de la Chute de l'Empire romain et du déclin de la civilisation, de l'an 250 a l'an 1000, Tomo 1, París, 1835.

"Smith, A. (1982). An Inquiry into the Nature and Causes of the Wealth of Nations, Vol. 1, Indianapolis, Liberty Classics.

» Staerman, E. M. (1989). "La caída del régimen esclavista”, en AA.VV., La transición del esclavismo al feudalismo, Madrid, Akal.

» Schtajerman, E. M. (1964). Die Krise der Sklavenhalterordnung im Westen des römischen Reiches, Berlín.

» Staerman, E. M. y Trofimova, M. K. (1979). La esclavitud en la ltalia imperial, Madrid, Akal.

» Taylor, Ch. (1975). Hegel, Cambridge, Cambridge University Press.

» Temperley, H. (1977). “Capitalism, Slavery and Ideology”, Past \& Present, 75, pp. 94-118.

» Thünen von, J. (1826). Der isolirte Staat in Beziehung auf Landwirthschaft und Nationalökonomie, Hamburgo. 
»Vera, D. (2010). “Ser esclavo de la tierra en la Italia tardoantigua: La racionalidad de una dependencia”, Anales de Historia Antigua, Medieval y Moderna, 42, pp. 35-53.

»Vera, D. (2007). “Essere 'schiavi de la terra' nell'Italia tardoantica: le razionalitá di una dipendenza”, Studia Histórica (Historia Antigua), 25, pp. 489-505.

"Vera, D. (1992-1993). "Schiavitù rurale e colonato nell'Italia imperiale”, Scienze dell’Antichitá. Storia, Archeologia, Antropologia, 6-7, pp. 291-339.

» Vinogradoff, P. (1905). The Growth of the Manor, Londres.

» Wallon, H. (1879). Histoire de l'esclavage dans l'Antiquité, Tomo 3, París.

» Wickham, Ch. (1988). “Marx, Sherlock Holmes, and Late Roman Commerce”, The Journal of Roman Studies, 78.

»Weber, M. (1922). Wirtschaft und Gesselschaft, Tübingen.

»Weber, M. (1891). Die Römische Agrargeschichte in ihrer Bedeutung, Stuttgart. 
